\title{
Historical analogues of the recent extreme minima observed in the Atlantic meridional overturning circulation at $26^{\circ} \mathrm{N}$
}

\author{
Adam T. Blaker · Joël J.-M. Hirschi • \\ Gerard McCarthy $\cdot$ Bablu Sinha $\cdot$ Sarah Taws • \\ Robert Marsh · Andrew Coward · Beverly de Cuevas
}

Received: 12 July 2013 / Accepted: 21 July 2014 / Published online: 9 August 2014

(C) Springer-Verlag Berlin Heidelberg 2014

\begin{abstract}
Observations of the Atlantic meridional overturning circulation (AMOC) by the RAPID $26^{\circ} \mathrm{N}$ array show a pronounced minimum in the northward transport over the winter of 2009/10, substantially lower than any observed since the initial deployment in April 2004. It was followed by a second minimum in the winter of 2010/2011. We demonstrate that ocean models forced with observed surface fluxes reproduce the observed minima. Examining output from five ocean model simulations we identify several historical events which exhibit similar characteristics to those observed in the winter of 2009/10, including instances of individual events, and two clear examples of pairs of events which happened in consecutive years, one in 1969/70 and another in 1978/79. In all cases the absolute minimum, associated with a short, sharp reduction in the Ekman component, occurs in winter. AMOC anomalies are coherent between the Equator and $50^{\circ} \mathrm{N}$ and in some cases propagation attributable to the poleward movement of the anomaly in the wind field is observed. We also observe a low frequency (decadal) mode of variability in the anomalies, associated with the North Atlantic Oscillation (NAO). Where pairs of events have occurred in consecutive years we find that atmospheric conditions during the first winter correspond to a strongly negative Arctic Oscillation (AO) index. Atmospheric conditions during the second winter are indicative of a more regional negative NAO phase, and we suggest that this persistence is linked to re-emergence of
\end{abstract}

A. T. Blaker $(\bowtie) \cdot$ J. J.-M. Hirschi · G. McCarthy $\cdot$ B. Sinha

A. Coward · B. de Cuevas

National Oceanography Centre, Southampton SO14 3ZH, UK

e-mail: atb299@noc.ac.uk

S. Taws $\cdot$ R. Marsh

University of Southampton, National Oceanography Centre,

Southampton SO14 3ZH, UK sea surface temperature anomalies in the North Atlantic for the events of $1969 / 70$ and 2009/10. The events of 1978/79 do not exhibit re-emergence, indicating that the atmospheric memory for this pair of events originates elsewhere. Observation of AO patterns associated with cold winters over northwest Europe may be indicative for the occurrence of a second extreme winter over northwest Europe.

Keywords AMOC $\cdot$ Minimum $\cdot$ Events $\cdot$ RAPID · Model $\cdot$ Observations $\cdot$ SST anomalies $\cdot$ Re-emergence

\section{Introduction}

The Atlantic meridional overturning circulation (AMOC) is part of the global ocean conveyor which transports warm and saline surface waters to the North Atlantic (Broeker 1987; Dickson and Brown 1994; Kuhlbrodt et al. 2007). On their journey towards the Nordic Seas these surface waters gradually become denser as they release heat to the atmosphere. Eventually, the increasing density leads to the sinking of the water masses and they are returned southward as cold and dense North Atlantic deep water. In the subtropical North Atlantic the surface and deep branches of the AMOC result in a maximum net northward heat transport of around 1.3 PW (Ganachaud and Wunsch 2000; Lumpkin and Speer 2007; Johns et al. 2011). The AMOC has been identified as a key ocean mechanism which contributes to the comparatively mild European climate. A large fraction of the heat released to the atmosphere by the AMOC is carried eastward towards Europe by the predominant westerly winds, leading to warmer temperatures in northwestern Europe than at similar latitudes in western Canada (Rhines and Häkkinen 2003; Broeker 1987; Sinha et al. 2012). The potential importance of the AMOC to the climate of the North 
Atlantic and Europe was a key motivation for the deployment of a transatlantic mooring array at $26.5^{\circ} \mathrm{N}$, known as the RAPID-WATCH/MOCHA/WBTS array (hereafter referred to as the $26^{\circ} \mathrm{N}$ array) (Rayner et al. 2011).

Observation- and model based studies have shown the AMOC transport at $26.5^{\circ} \mathrm{N}$ to exhibit substantial variability on short timescales (Cunningham et al. 2007; Kanzow et al. 2009, 2010; Hirschi and Marotzke 2007; Baehr et al. 2007, 2009; Balan Sarojini et al. 2011; McCarthy et al. 2012). The observed intra-annual peak-to-peak range of the AMOC, computed using daily means, can be as large as $30 \mathrm{~Sv}$ (Cunningham et al. 2007). Between April 2004 and April 2009, the AMOC transport at $26.5^{\circ} \mathrm{N}$ has a mean of $18.5 \mathrm{~Sv}$, with a standard deviation of $4.7 \mathrm{~Sv}$, when computed using 5 day means. The origin of the observed AMOC variability is only partly understood. Some variability, such as the observed seasonality of the AMOC and interannual variability seen in numerical models, can be linked to the seasonal variability in the wind stress curl along the African coast (Kanzow et al. 2010; Chidichimo et al. 2010; Sinha et al. 2013).

Observations from the $26^{\circ} \mathrm{N}$ array revealed a recent strong short-term reduction in the strength of the AMOC (McCarthy et al. 2012). The event lasted for 3-4 months over the late winter and early spring of 2009/2010, and resulted in the April-March annual average for that year reducing to $12.8 \mathrm{~Sv}, 30 \%$ lower than the mean for the previous 5 years. This is the first such event to occur in the 7 year long record from the $26^{\circ} \mathrm{N}$ array, and it is not known whether events of this kind have occurred in the past. It was followed the year after by a similarly anomalous minimum, raising the question of whether the two events were linked, or whether they occurred consecutively by coincidence. To try and address this question we employ ocean models forced with historical observations of surface fluxes. We examine the characteristics of anomalously low AMOC events in five $1 / 4^{\circ}$ model integrations which all cover the period 1958-2001 and two further model integrations, one at $1 / 4^{\circ}$ and one at $1 / 12^{\circ}$, which cover the period between 2001 and 2011.

Outline The remainder of this article is organized as follows. Section 2 describes the observation based datasets and the ensemble of model simulations used. Our analysis is presented in Sect. 3. Finally, we summarise our findings in Sect. 4.

\section{Methods}

\subsection{Observation based datasets}

For the analysis presented here we use the following observation based datasets.
The AMOC measured by the $26^{\circ} \mathrm{N}$ array is the sum of the transport measured through the Florida Straits, the geostrophic component derived from measurements of the density difference between the eastern and western boundaries, Ekman transport derived from CCMP/Quikscat winds, and a compensation term which ensures that there is no net transport through the section (Rayner et al. 2011). Ocean models suggest that the sum of these is a close approximation to the true AMOC which one could compute if the northward velocity at all points through the section were known (Hirschi and Marotzke 2007; Hirschi et al. 2003). Data from the $26^{\circ} \mathrm{N}$ array (http://www.rapid.ac.uk) are provided at 12 hourly resolution with a 10 day low pass filter applied. Observations of all component time series are available from April 2004 to present. For our analysis we compute 5 day averages to facilitate comparison with the model simulations, for which output is stored as 5 day averages.

To explore the geographical nature of the events we use monthly mean sea level pressure (SLP) and surface air temperature (SAT) data from the NCEP/NCAR reanalysis dataset (Kalnay et al. 1996). We relate the events identified to the monthly indices of the North Atlantic and Arctic Oscillations following Hurrell (1995) (NCAR 2012a, b). To examine the mechanism of re-emergence we make use of SST data from the NOAA optimal interpolation dataset (Reynolds et al. 2002) http://www.esrl.noaa. gov/psd/ and also of the ENACT (EN3) reanalysis from the UK Met Office (Ingleby and Huddleston 2007) http://www.metoffice.gov.uk/hadobs/en3/.

\subsection{Model description and runs}

We use a total of seven NEMO (Nucleus for European Modelling of the Ocean) ORCA (Madec 2008) model integrations, most of which were set up in the DRAKKAR project (DRAKKAR Group 2007; Barnier et al. 2006; Madec 2008), and one run from the RAPID-WATCH VALOR project. Table 1 details the runs.

Five simulations start from 1958, and form the ensemble which we will analyse in this paper. Aspects of the AMOC in some of these runs have been published previously (Grist et al. 2010, 2012; Blaker et al. 2012; Hirschi et al. 2013; Duchez et al. 2014b). All of these simulations are on the ORCA025 grid, for which horizontal resolution is nominally $1 / 4^{\circ}$. South of $20^{\circ} \mathrm{N}$ the model grid is isotropic Mercator, and north of $20^{\circ} \mathrm{N}$ the grid becomes quasi-isotropic bipolar, with poles located in Canada and Siberia to avoid numerical instability associated with convergence of the meridians at the geographic North Pole. At the Equator the resolution is approximately $27.75 \mathrm{~km}$, becoming finer at higher latitudes such that at $60^{\circ} \mathrm{N} / \mathrm{S}$ it becomes $13.8 \mathrm{~km}$. The models in the ensemble include both 64 and 75 vertical levels with a grid spacing increasing from $6 \mathrm{~m}$ near the surface $(1 \mathrm{~m}$ for the 
Table 1 This table shows the model configurations used

\begin{tabular}{llllll}
\hline Run ID & $\begin{array}{l}\text { Code } \\
\text { version }\end{array}$ & $\begin{array}{l}\text { Ice } \\
\text { model }\end{array}$ & Levels & Forcing & Period \\
\hline N102 & v2.3 & LIM2 & 64 & DFS3 & $1958-2001$ \\
N112 & v2.3 & LIM2 & 64 & DFS3 & $1958-2001$ \\
N200 & v2.3 & LIM2 & 64 & DFS4.1 & $1958-2001$ \\
N206 & v3.2 & LIM2 & 75 & CORE2 & $1958-2007$ \\
N300 & v3.0 & LIM3 & 64 & DFS3 & $1958-2001$ \\
VN206 & v3.2 & LIM2 & 75 & ERA Interim & $1989-2011$ \\
ORCA12 & v3.2/ & LIM2 & 75 & DFS4.1/ & $1978-2010$ \\
& v3.3.1 & & & DFS5.1.1 &
\end{tabular}

All are ORCA025 $\left(1 / 4^{\circ}\right)$ except ORCA12, which is $1 / 12^{\circ}$. The ORCA12 simulation includes a minor code change in 1989 , and a change in surface forcing in 2007 in order to extend out to 2010

75 level runs) to $250 \mathrm{~m}$ at $5,500 \mathrm{~m}$. Bottom topography is represented as partial steps and bathymetry is derived from ETOPO2 (U.S. Department of Commerce 2006). To prevent excessive drifts in global salinity due to deficiencies in the fresh water forcing, sea surface salinity is relaxed towards climatology with a piston velocity of $33.33 \mathrm{~mm} / \mathrm{day} / \mathrm{psu}$. Sea ice is represented by the Louvain-la-Neuve Ice Model version 2 (LIM2) sea-ice model (Timmerman et al. 2005), and version 3 of the same for one of the runs.

Climatological initial conditions for temperature and salinity were taken in January from PHC2.1 (Steele et al. 2001) at high latitudes, MEDATLAS (Jourdan et al. 1998) in the Mediterranean, and Levitus et al. (1998) elsewhere. These initial conditions were applied to all runs with the exception of N112, which started from the final state of N102, and VN206, which started from the final state of N206. Starting from rest the models simulate the period indicated in the right hand column of Table 1, with surface forcing comprising of 6-hourly mean momentum fields, daily mean radiation fields and monthly mean precipitation fields supplied by the DFS3, DFS4.1 and CORE2 datasets (Brodeau et al. 2010; Large and Yeager 2004, 2008) and linearly interpolated from the time mean fields by the model. Model output is stored as 5-day averages, although for disk storage considerations, we have only retained monthly mean values for some of the older datasets.

One $1 / 4^{\circ}$ run, VN206, is forced by the ERA Interim dataset (Dee et al. 2011) and extends to March 2011. We also examine the output of a recently completed ORCA12 $\left(1 / 12^{\circ}\right)$ run, which again uses the NEMO ORCA code, but is now eddy resolving for much of the global ocean.

The ensemble of model integrations we have compiled here are all closely related. They are runs of the same model with minor/moderate variations in the code version, applied surface forcing, ice model used and intial conditions, and all reproduce plausible ocean states. For each of the model runs we compute the $\mathrm{AMOC}$ and component parts equivalent to those which are measured and used to construct the time series at $26.5^{\circ} \mathrm{N}$. Florida Straits transport in the model integrations is computed as the integral of the meridional velocity through the Florida Straits. The upper mid ocean (UMO) component is computed by integrating the east-west density difference derived geostrophic transport across the basin. Ekman transport is computed using the surface wind stress. A uniform compensation velocity which ensures no net volume transport through the section is applied. Details of the component decomposition method are provided in the Appendix.

\section{AMOC analysis}

\subsection{Comparison with observations}

In order to establish whether the NEMO ORCA model is able to capture the features of the events seen in the observations we first examine model output from runs VN206 and ORCA12 (Fig. 1; see Table 1 for details of these runs). These are the only experiments which cover the recently observed minima. The transport and components from VN206 are shown in Fig. 1a, and for ORCA12 in Fig. 1b. The components measured by the mooring array at $26.5^{\circ} \mathrm{N}$ are shown in each plot as thin, slightly darker lines of the same shade. The mean, standard deviation and correlation between the modelled and observed time series are presented in Table 2. As expected, the Ekman component is well represented in the simulations (correlations of 0.88 and 0.84) although both have a weaker mean and standard deviation than reported from observations. Both simulations exhibit weaker Florida Straits (FS) transports than observed. The mean FS transport in VN206 is $5.5 \mathrm{~Sv}(17 \%)$ weaker than observed. ORCA12 captures the mean transport better, but underestimates the variability. It is interesting to note that FS transport variability is even lower in ORCA12 than in VN206. The variability of the FS transport (and of any other western boundary current) depends on the choice of the lateral boundary condition. Using no-slip conditions has been shown to destabilise western boundary currents leading to more mesoscale ocean eddies and variability close to lateral boundaries (Quartly et al. 2013). This behaviour has also been observed in a suite of ORCA12 simulations conducted in the framework of the DRAKKAR project (Deshayes et al. 2013) where the variability of western boundary currents is found to be systematically higher when using partial slip conditions. Correlations between the modelled and observed FS transport are low (0.22 and 0.35), indicating that a large fraction of the FS variability cannot directly be attributed to the surface forcing. The correlation between the FS transport time series from the two model runs is also low (0.35), which suggests that the FS transport variability is dominated by internal variability. Both models capture the 
(a) 40

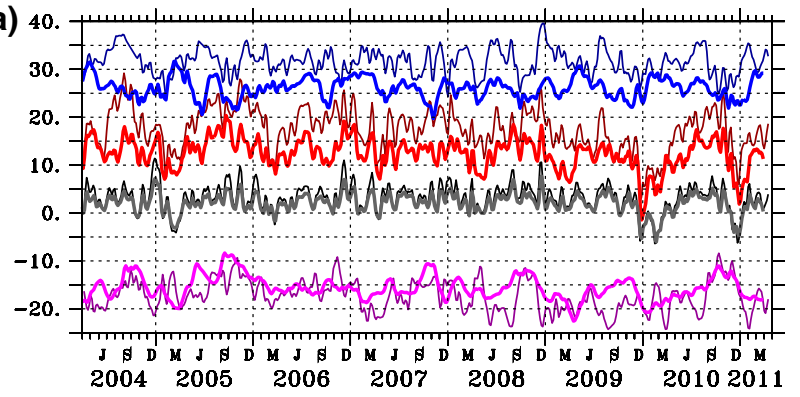

(b)

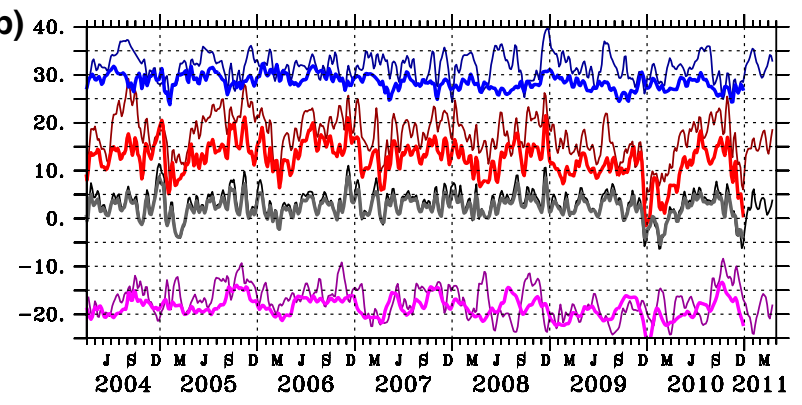

(c)

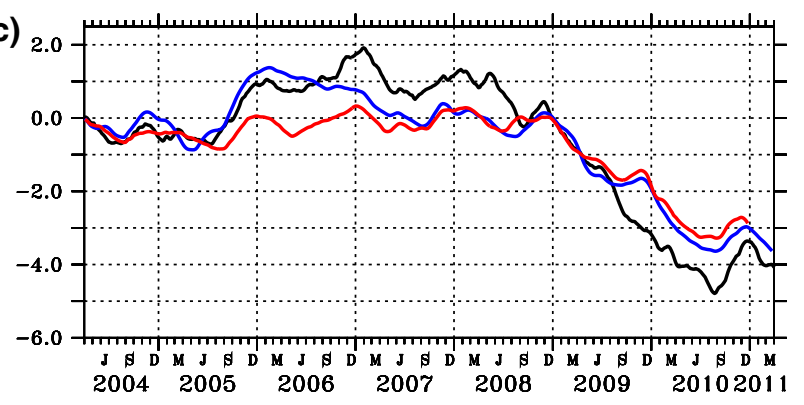

Fig. 1 Comparison of the component time series of the Atlantic MOC between the simulations a VN206 and b ORCA12 and the RAPID observations. In the top two panels the model time series are shown in bold lines, and the observations are shown in thin lines: the Florida Straits transport (blue), Ekman (black), upper mid ocean (UMO) transport (magenta), and total AMOC (red). A slightly darker shade of the same colour is used for the observations to aid identification where lines overlay. Units are Sverdrups $\left(1 S v=1 \times 10^{6} \mathrm{~m}^{3} \mathrm{~s}^{-1}\right)$ and data are smoothed with a 15 day Parzen filter. c Shows the accumulated transport anomaly for the UMO component of the transport for the RAPID observations (black), VN206 (blue) and ORCA12 (red). Transport anomalies are defined to be the UMO component with the time average for the period April 2004 to December 2008 subtracted. The anomalous transports are then accumulated over time. Units are Sverdrup years

mean UMO transport. They also appear to capture the low frequency (seasonal and longer) variability of the observed UMO time series, but fail to capture the higher frequency variability (Fig. 1). This behaviour may arise because the low frequency variability of the UMO transport at $26.5^{\circ} \mathrm{N}$ is well approximated by the surface forced Sverdrup transport (Duchez et al. 2014b). The seasonal cycle of the total AMOC and the UMO component are well represented in the models, with respect to both the timing and amplitude (Duchez et al. 2014a).
Table 2 This table shows the mean and standard deviation (brackets) for each time series shown in Fig. 1

\begin{tabular}{lclll}
\hline & Obs & VN206 & ORCA12 & \\
\hline AMOC & $17.47(4.78)$ & $12.37(3.26)$ & $12.57(3.72)$ & \\
& & 0.74 & 0.73 & $(0.83)$ \\
Florida Strait & \multirow{2}{*}{$31.56(3.02)$} & $26.03(2.15)$ & $28.57(1.56)$ & \\
& & 0.22 & 0.35 & $(0.35)$ \\
Ekman & \multirow{2}{*}{$3.19(3.32)$} & $2.04(2.08)$ & $2.56(2.26)$ & \\
& & 0.88 & 0.84 & $(0.93)$ \\
UMO & $-17.22(3.47)$ & $-15.66(2.49)$ & $-18.44(2.07)$ & \\
& & 0.47 & 0.43 & $(0.65)$ \\
\hline
\end{tabular}

Correlations between each model and the observations, based on 5 day mean values, are given in italics. Shown in brackets in the right hand column is the correlation of each time series between the two models

The extreme events which occur during the winters of 09/10 and 10/11 both reach their peak in late December. Taking a 30 day average of the observations and subtracting from the time mean observational values, the anomalous Ekman component contributes $52 \%$ of the first AMOC minimum and around $80 \%$ of the second. Both simulations (ORCA12 and VN206) agree well with the observations for the first event (55 and $51 \%$ respectively). For the second event the Ekman component contributes $50 \%$ (ORCA12) and $46 \%$ (VN206) for the two simulations. An observed negative anomaly in the UMO transport, which began early in 2009 and was associated with a partial shift of the circulation from the deep overturning to the upper gyre circulation, was found to contribute significantly to the minimum event of 2009/10 (McCarthy et al. 2012). To establish how well the UMO anomaly is represented by the simulations we compute the accumulated UMO transport anomaly in the manner of Bryden et al. (2014) (Fig. 1c). The accumulated transport anomaly is the cumulative summation of UMO anomalies from April 2004 (the start of the observational period) to the end of the simulations/observations. Presenting the anomalies in this way emphasises anomalies of a consistent sign, whilst reducing the visual effect of differences in the timing of short term variability between the simulations and observations. It indicates that the models also capture around two thirds of the anomalous transport associated with the UMO.

These figures indicate that to first order the extreme minima in the AMOC are, consistent with Zhao and Johns (2014), atmospherically forced processes, which NEMO is able to represent.

\subsection{Historical analogues}

The array measurements only extend back as far as 2004, but our ocean models are typically forced with atmospheric 


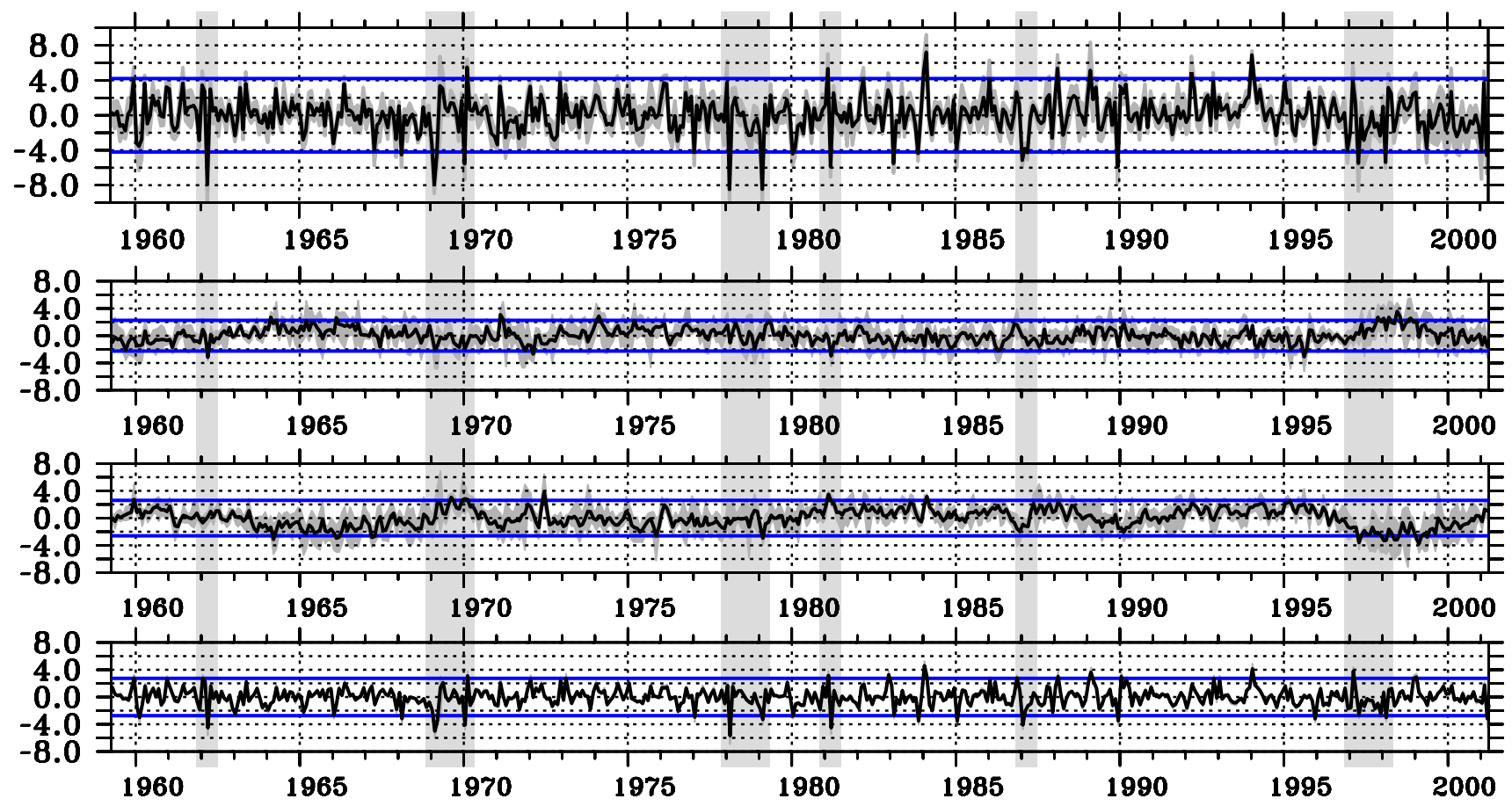

Fig. 2 Composite (monthly mean) of detrended time series with mean seasonal cycle removed for the years 1959-2001 from the 5 ORCA025 hindcasts. AMOC (Top), FST (upper middle), GEO (lower middle) and EKM (bottom). Blue lines denote $+/-2$ standard

observations from as early as 1958. Since we have confidence that NEMO ORCA is able to reproduce events such as the ones observed in 2009/10 given only surface forcing, we can examine the time series of the AMOC from our ensemble of historical model runs for examples of similar events.

We construct a composite of the AMOC anomalies $\left(\Psi^{\prime}\right)$ from the five eddy permitting hindcasts that span the time period 1958-2001 by removing the linear trend from each ensemble member and then removing the seasonal cycle. The AMOC anomalies are then averaged to produce the ensemble mean (Fig. 2). This composite reveals several strongly negative events, some substantially in excess of 2 standard deviations from the mean. There is a strong negative event in 1962/63, one in 1980/81 and another in $1983 / 84$. There is also a minimum in $1986 / 87$ with a duration of 3-4 months. We can also identify two pairs of events, one pair in 1968/69 and 1969/70, and another pair in $1977 / 78$ and $1978 / 79$. One further example in the time series which may also be a weaker analogue of the 2009/10 event occurs during 1996/97 and 1997/98. The event in the winter of 1996/97 occurs slightly later (around March) than other events in the time series (typically January-February). It coincides with an anomalously strong northward Ekman transport anomaly in February, which we suggest is likely to have reduced the impact and altered the timing of the negative event. deviations for each component. Grey underlay denotes the ensemble spread for each month. Units are Sv. The events discussed in the text are indicated using vertical grey bars

From the observed events we know that a large fraction of the minimum arises from the Ekman component [Fig. 1, and also McCarthy et al. (2012)], and the high correlation between the Ekman component and the AMOC (0.87) can be seen in Fig. 2a, d. It is worth noting that the ensemble spread for the Ekman component is very small, which is a reflection of the similarities among the forcing datasets and how strongly the Ekman component is controlled by the surface forcing. Whilst variability of the Ekman component is the largest single contributor, it does not explain all of the variability in the AMOC. The value of two standard deviations in the AMOC is $4 \mathrm{~Sv}$. Two standard deviations of the Ekman component alone is $2.7 \mathrm{~Sv}$, whilst the variability associated with the other components combined is slightly higher than this at $2.95 \mathrm{~Sv}$. However, we note that for months which exhibit a negative AMOC anomaly of greater than 2 standard deviations, we find that on average the Ekman component contributes $62 \%$ of the anomaly. Some interaction between the FS transport and the geostrophic transport can also be seen in Fig. 2b, c, which have a correlation of -0.55 . This is partly attributable to the inclusion of the FS compensation in the UMO transport, and partly to variation in the path of the Gulf Stream, with some fraction of the transport occasionally passing to the east of the Bahamas instead of through the FS. This may be an artefact of the model resolution. The ensemble spread is 
Fig. 3 Composite (monthly mean) of the AMOC with the mean and seasonal cycle removed as a function of latitude. a Time period from April 1959 through till March 2001, and $\mathbf{b}$ expansion of time period from September 1977 through till August 1979. The line plot above $\mathbf{a}$ is the meridional average of the transport anomaly presented in a. The events discussed in the text are indicated with * (pair events) and + (single events). Units are Sv

Fig. 4 Composite (monthly mean) of the Ekman component with the mean and seasonal cycle removed as a function of latitude. a Time period from April 1959 through till March 2001, and $\mathbf{b}$ expansion of time period from September 1977 through till August 1979. The events discussed in the text are indicated with * (pair events) and + (single events). Units are $\mathrm{Sv}$

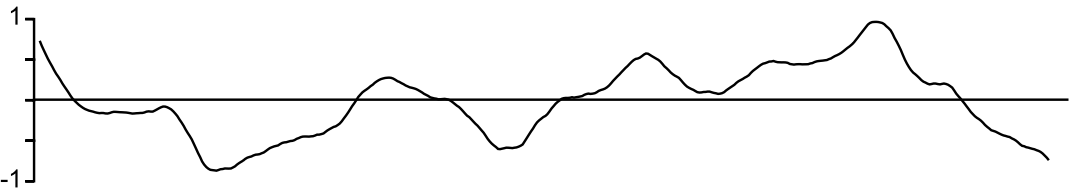

(a)

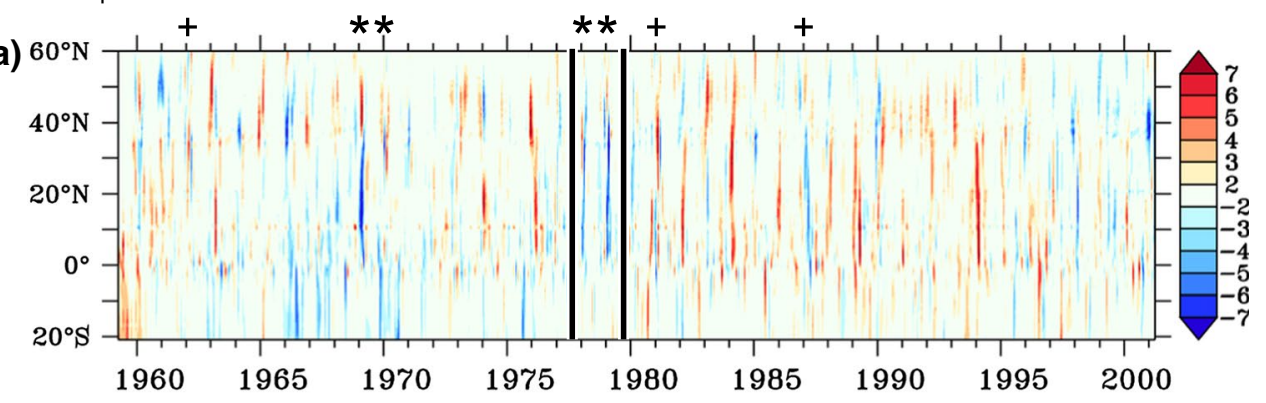

(b)
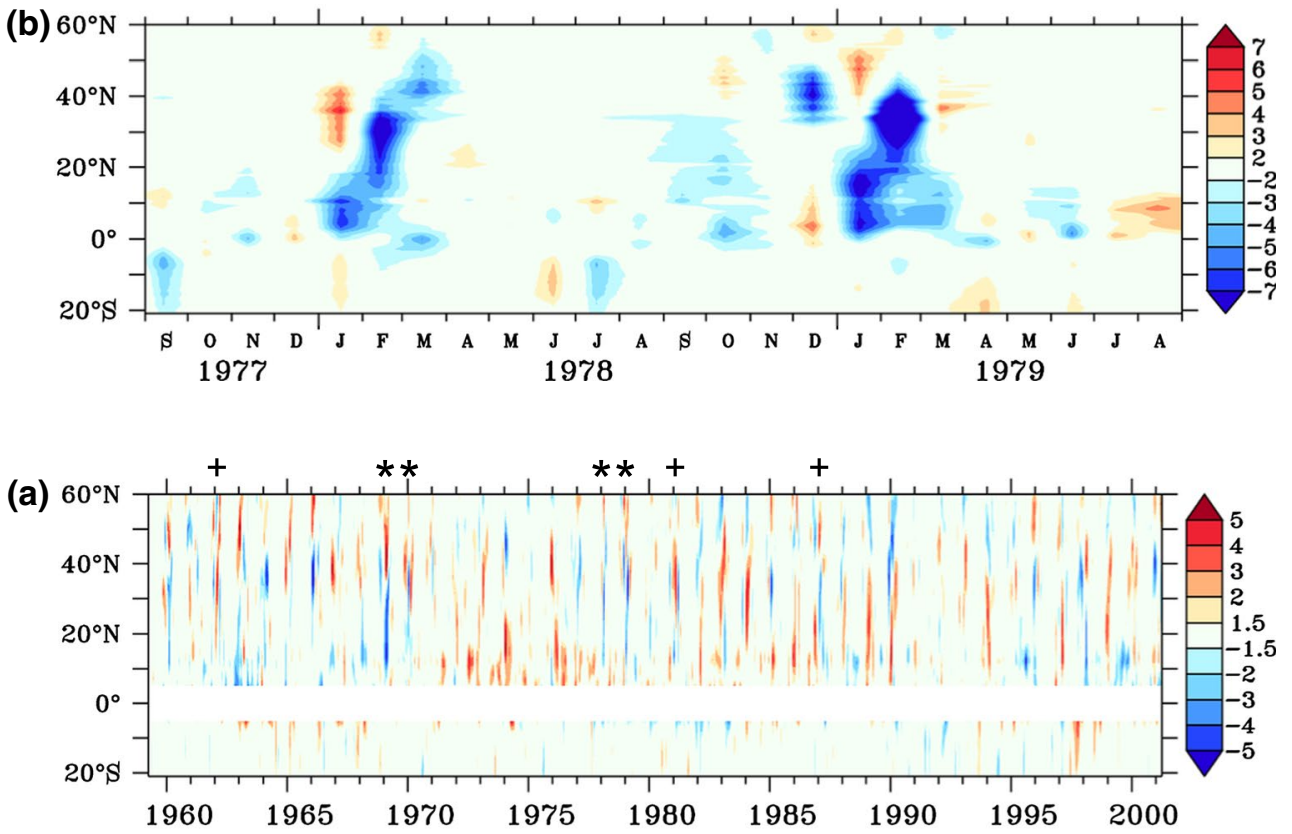

(b)

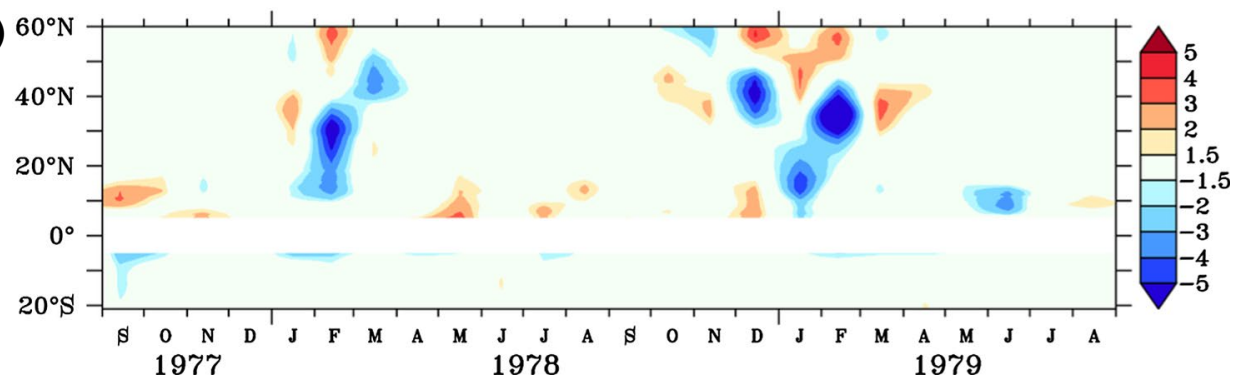

large for the FS transport and the geostrophic transport, and this reflects the differences in timings of short timescale chaotic events (e.g. mesoscale ocean eddies, Gulf Stream meanders), which account for about $30 \%$ of the total AMOC variability (Hirschi et al. 2013).

The distribution of extreme AMOC events is asymmetric. There are only two positive anomalies stronger than $6 \mathrm{~Sv}$, one in 1984 and one in 1994, both of which coincide with strong positive anomalies in the Ekman transport. In contrast there are 6 negative events which exceed $6 \mathrm{~Sv}$.
However, the time series is too short and there are insufficient events to say whether this is statistically significant.

\subsection{Latitudinal characteristics}

We compute the anomalies of the AMOC for the ensemble mean as a function of latitude and time (Fig. 3), revealing that the anomalies in the AMOC are short (order 1-2 months) at all latitudes. It is also interesting to note that the anomalies, both of positive and negative sign, 


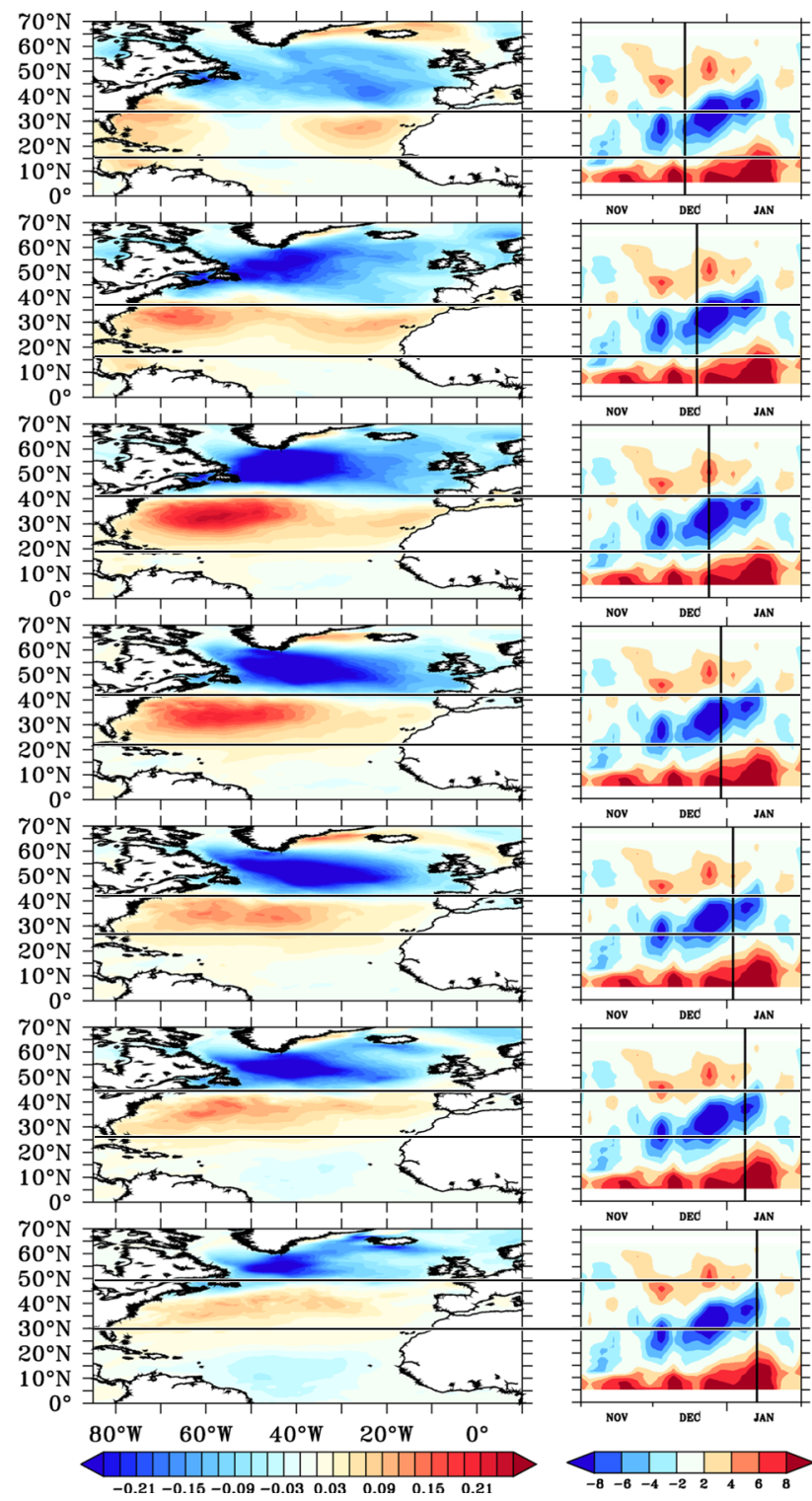

Fig. 5 Sequence of images showing the spatial pattern of zonal wind stress anomalies $\left(\mathrm{Nm}^{-2}\right)$ over the N. Atlantic (left) at the time indicated by the vertical thick black line on the Hovmöller diagram (right). The Hovmöller diagram depicts the anomalous Ekman transport for the winter of 2010/11 (Fig. 3b). Horizontal black lines intersect the vertical thick black line at the $-2 \mathrm{~Sv}$ contour interval, and extend across the panels on the left to indicate the meridional extent of the wind stress anomaly. The data plotted here are 5 day mean values from simulation VN206, smoothed using a 15 day Parzen filter

predominantly occur during the boreal winter months. This reflects the much greater variability in northern hemisphere atmospheric circulation during the winter months, whilst the summers are more stable and therefore less likely to give rise to extreme anomalies. Anomalies are more frequent near the Equator and around $40^{\circ} \mathrm{N}$ where the Gulf Stream separates from the coast and becomes more zonal, and are typically confined to smaller latitudinal extents as would be expected for anomalies which arise due to the presence of strong eddy or wave activity. There are several anomalies which have a much greater latitudinal extent, from near the Equator to $50^{\circ} \mathrm{N}$.

Expanding the time axis around a region of interest, such as the strong minima events observed during the winters of $1977 / 78$ and 1978/79 (Fig. 3b) shows that many of the anomalies propagate poleward, covering $50^{\circ}$ of latitude in 1-2 months. Anomalies start near the Equator in December/January and reach $40-50^{\circ} \mathrm{N}$ by March/April. The similarity between the Ekman component (Fig. 4) and the AMOC (Fig. 3) indicates that the propagation is a poleward shift of the Ekman anomaly caused by meridionally propagating anomalies in the mean surface wind field. This characteristic is not specifically associated with the extreme anomalies. It also occurs in other years, typically during the winter months.

To further examine the northward propagation of the AMOC anomalies we examine in detail the anomalous Ekman transport from recent winter 2010/11. Figure 5 illustrates how the zonal wind stress anomalies over the North Atlantic change over time by stepping through 35 days which cover the northward propagation of this anomaly. A positive anomaly, corresponding to a weakening of the easterly winds, forms and begins to strengthen over the western half of the Atlantic basin between 15 and $35^{\circ} \mathrm{N}$ in mid December. Positive (i.e. westerly) anomalies north of the Equator result in an anomalous southward Ekman transport. The positive anomaly intensifies over the next 10 days and begins to propagate north and spread across the basin. By early January the anomaly is located between 26 and $45^{\circ} \mathrm{N}$, and by mid January it begins to weaken, the sourthernmost part of the anomaly weakening first. The AMOC anomaly associated with this anomalous wind stress can exceed $-12 \mathrm{~Sv}$ for a 5 day mean.

\subsection{Atmospheric and SST conditions}

One of the most prominent atmospheric features in the North Atlantic sector is the North Atlantic Oscillation (NAO). The NAO is an important mode of climate variability which influences the climate over the North Atlantic and much of northern Europe, particularly during the winter months. The NAO can be represented by an index, and the one we use is computed from winter (DJFM) differences between the normalised SLP measured at Lisbon, Portugal and Stykkisholmur, Iceland (Fig. 6a, Hurrell 1995; NCAR 2012a). When the NAO index is negative the corresponding SLP anomalies (low over Azores, high over Iceland) drive a southward excursion of the core of the jet stream, which brings with it cold European winters (Luo et al. 2010). The low frequency 
Fig. 6 Time series of a the winter (DJFM) NAO index, and b the winter (DJFM) AO index (Hurrell 1995; NCAR 2012a). The events discussed in the text are indicated with $*$ (pair events) and + (single events)
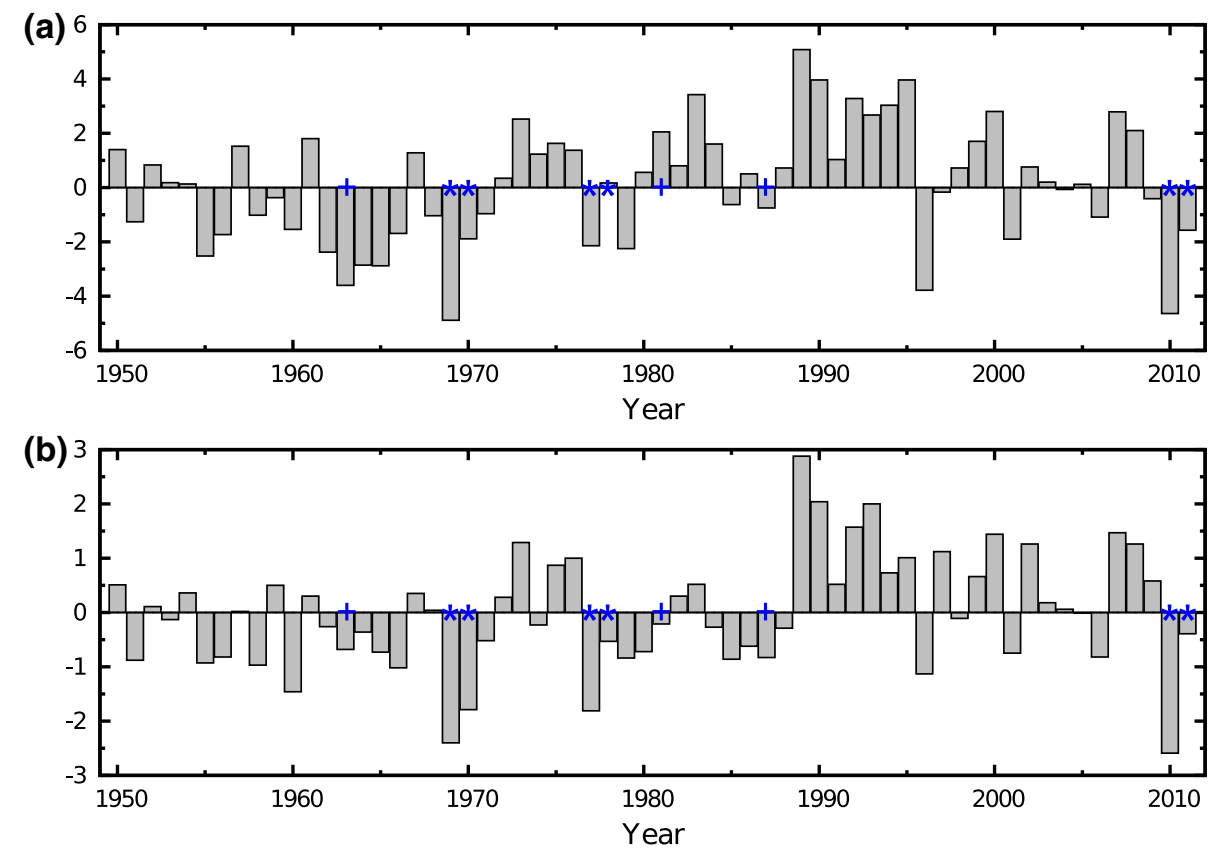

mode of variability which appears in the AMOC anomalies (Fig. 3) is positively correlated (0.65) with the winter NAO variability (Fig. 6a). The winter mean NAO index is predominantly negative between 1950 and 1980 and then transitions to being predominantly positive from 1980 to 2000 . The ocean is thought to influence the low frequency component of the NAO (Bellucci et al. 2008; Marshall et al. 2000; D'Andrea et al. 2005; Gastineau et al. 2013; Ciasto et al. 2011; Sevellec and Fedorov 2013). A recent study by Sonnewald et al. (2013) indicates that upper ocean heat content variability in the North Atlantic is dominated by the ocean heat transport on longer than seasonal timescales. This is supported by an observation based study which examines the ocean heat content, SST and surface fluxes associated with the events of 2009-2011, and finds that reduction in the strength of the AMOC was primarily responsible for the observed anomalous heat content (Bryden et al. 2014). Potential predictability of the AMOC can account for forecast skill of North Atlantic SST, particularly for the subpolar gyre (see Hermanson et al. (2014) and references therein). Together, this increasing body of literature supports the idea that the ocean is an important contributor to low frequency atmospheric variability.

Examining first the most recent events, the winters of 2009/10 and 2010/11 both exhibited a strongly negative NAO index, with December 2010 recording the second lowest NAO index $(-4.62)$ since records began in 1825 (Osborn 2011). Spatial plots of the winter mean SLP for the winters of 2009/10 and 2010/11 (Fig. 7e, f) show that these winters, that of 2009/10 in particular, bear the characteristics of a negative Arctic oscillation (AO) pattern with a pronounced anomaly in the N. Atlantic sector and over Russia. The AO is another pattern of atmospheric variability closely related to the NAO (Fig. 6b), and is derived using the first principle component of winter (DJFM) SLP anomalies poleward of $20^{\circ} \mathrm{N}$ (NCAR 2012b). However, whilst the two indices are closely related, strongly negative AO years do not necessarily coincide with a strongly negative NAO. The NAO is considered by some to be a regional expression of the $\mathrm{AO}$ (see e.g. Thompson and Wallace 2000), and Wallace (2000) suggested that they can be considered manifestations of the same basic phenomenon. February 2010 recorded the lowest AO index (-4.266) since reliable records began in 1950 (L'Heureux et al. 2010; NOAA 2013). Similar spatial plots for the winters of the other pairs of events in 1968/69-1969/70 and 1977/78-1978/79 reveal that the winters of the first year of the pair all exhibit similar strong negative AO conditions. The anomaly patterns, particularly over the North Atlantic sector, are seen in each case to persist in the following winter.

In comparison if we examine the winter mean SLP for three winters in which strong individual AMOC anomaly events occur $(1962 / 63,1980 / 81,1987 / 88)$ the anomaly pattern is not consistent (Fig. 8). For the winter of 1962/63 a strong negative NAO event occurs, but for the winters of 1980/81 and 1987/88 the anomalies indicate a negative Atlantic ridge (AR) weather pattern. The subsequent winters do not retain the same SLP anomaly pattern over the N. Atlantic sector. The winter of 1963/64 exhibits a negative AR pattern, whilst $1981 / 82$ shows a similarly strong positive occurence of the AR pattern. The winter of 1988/89 exhibits a weak negative NAO pattern. 

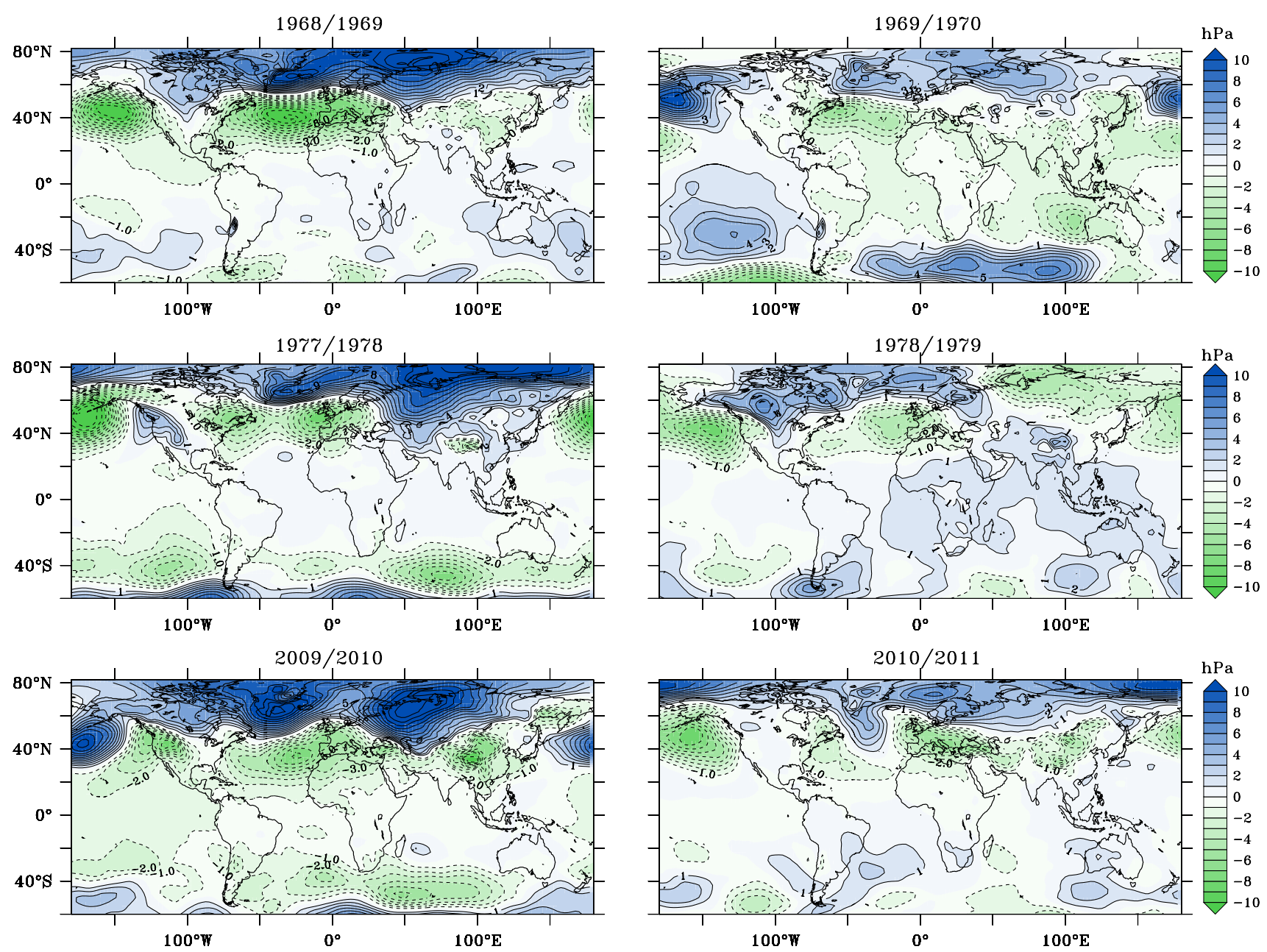

Fig. 7 Winter mean sea level pressure anomalies calculated from the NCEP/NCAR reanalysis dataset for years in which a pair of AMOC minima are seen in consecutive winters. Events shown are 1969/70

Examining SAT anomalies for 1968/69-1969/70, 1977/78-1978/79 and 2009/10-2010/11 reveals a widespread cool anomaly across much of Siberia for the winters of the pairs of events (Fig. 9). For the years associated with single events cool anomalies are weaker and located over Europe (Fig. 10). The temperature anomalies associated with the pairs of events also show the tendency to persist for the following winter. This is most pronounced for the winters of 2009/10 and 2010/11 where the cold anomalies over Eurasia and North America occur mainly over the same regions. For the other two pairs of events the largest anomalies in the $2 \mathrm{~m}$ air temperature vary in location from one year to the next. For the 1968/69-1969/70 pair the first event coincided with exceptionally low temperatures over Siberia (e.g. Hirschi and Sinha 2007), whilst anomalies were small over Europe. During the second event in contrast the coldest anomalies occurred over Northwestern Europe. A large variability in the temperature distribution

(top), 1978/79 (middle), and 2010/11 (bottom). The winter of the first year is shown on the left and for the following year on the right

in different NAO negative winters is consistent with earlier studies (e.g. Heape et al. 2013).

Taws et al. (2011) present evidence that SST anomaly patterns in the North Atlantic during the winter of 2010/11 arose from the re-emergence of a remnant tripole pattern of SST anomalies formed during the winter of 2009/2010 (Fig. 11). The anomaly pattern is characterised by a tripole of warm anomalies in and around the Labrador Sea, cold anomalies which extend across much of the North Atlantic from around 25 to $50^{\circ} \mathrm{N}$, and a warm anomaly south of $25^{\circ} \mathrm{N}$. The SST anomalies for January and February of 2010 (not shown) are similar in amplitude and spatial pattern to March. Re-emergence of temperature anomalies provides a mechanism by which anomalous SST conditions can persist from one winter to the next (Alexander and Deser 1995). A recent paper by Buchan et al. (2014) examines the response of a coupled climate model to the inclusion of SST anomalies observed during 

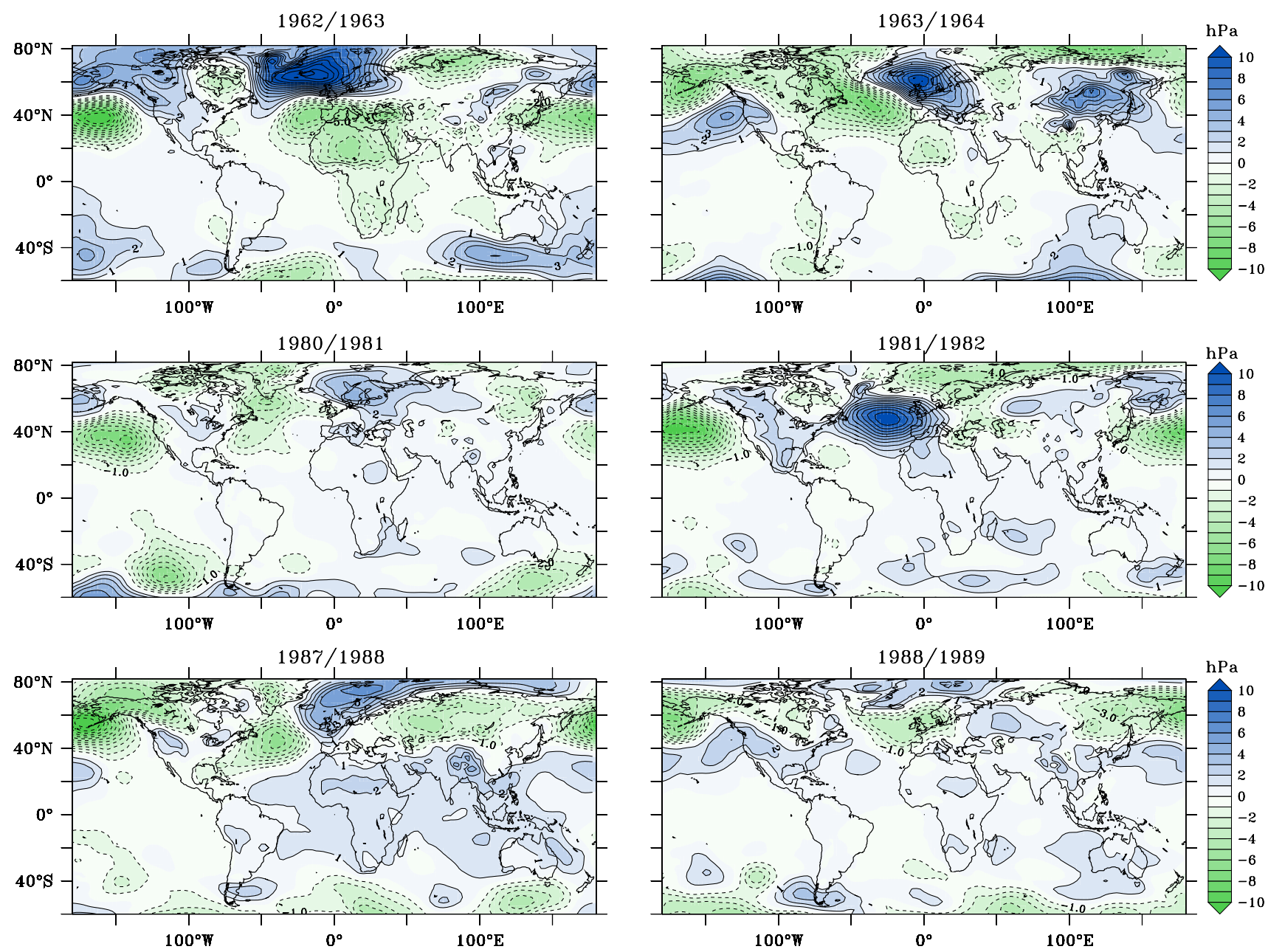

Fig. 8 Winter mean sea level pressure anomalies calculated from the NCEP/NCAR reanalysis dataset for years in which a single minima is seen. Events shown are the winters of 1962/63 (top), 1980/81 (mid-

dle), and 1986/87 (bottom). The winter of this year is shown on the left and for the following year when no AMOC minima is seen on the right

the years of 2009 and 2010. The inclusion of the anomalies is shown to result in a statistically significant negative shift of the NAO in the model, supporting the idea that reemergence of an SST anomaly pattern may influence the atmosphere and contribute to the necessary conditions for persistence of negative NAO conditions and extreme cold winter weather over northwest Europe. An earlier study by Cassou et al. (2007) also found the SST anomaly pattern associated with re-emergence led to an atmospheric circulation which resembled the one from the previous winter.

The atmospheric conditions during the winters of $1968 / 69$ and $1977 / 78$ were similar to those experienced in the winter of 2009/10, with the NAO and AO indices in an extreme negative state (Fig. 6). Taws (2013) examined SST fields from EN3 for evidence of previous re-emergence signatures. Figure 12a shows lagged pattern correlations referenced to March (March through to April of the following

year) of SST anomalies for the North Atlantic computed from EN3 (Ingleby and Huddleston 2007). It shows that both March 2010 and the following winter and March 1969 and the following winter exhibited higher levels of correlation (between 1 and 2 standard deviations of the 1960-2011 period) between subsequent winters, and the similarity of the timing and strength of the correlation suggests that both periods experienced re-emergence events. March of 1978 and the following winter show no significant increased correlation, suggesting that re-emergence did not occur during this period. None of the other years show a strong indication of re-emergence. Figure $12 \mathrm{~b}$ is equivalent to $12 \mathrm{a}$, but instead shows a composite of the lagged pattern correlations computed from SST anomalies in the ensemble of ORCA025 models. The models also show significantly higher correlations between the winter months of 1968 and 1969, in this case between 2 and 3 standard deviations, indicating that there was a re-emergence event. The model 

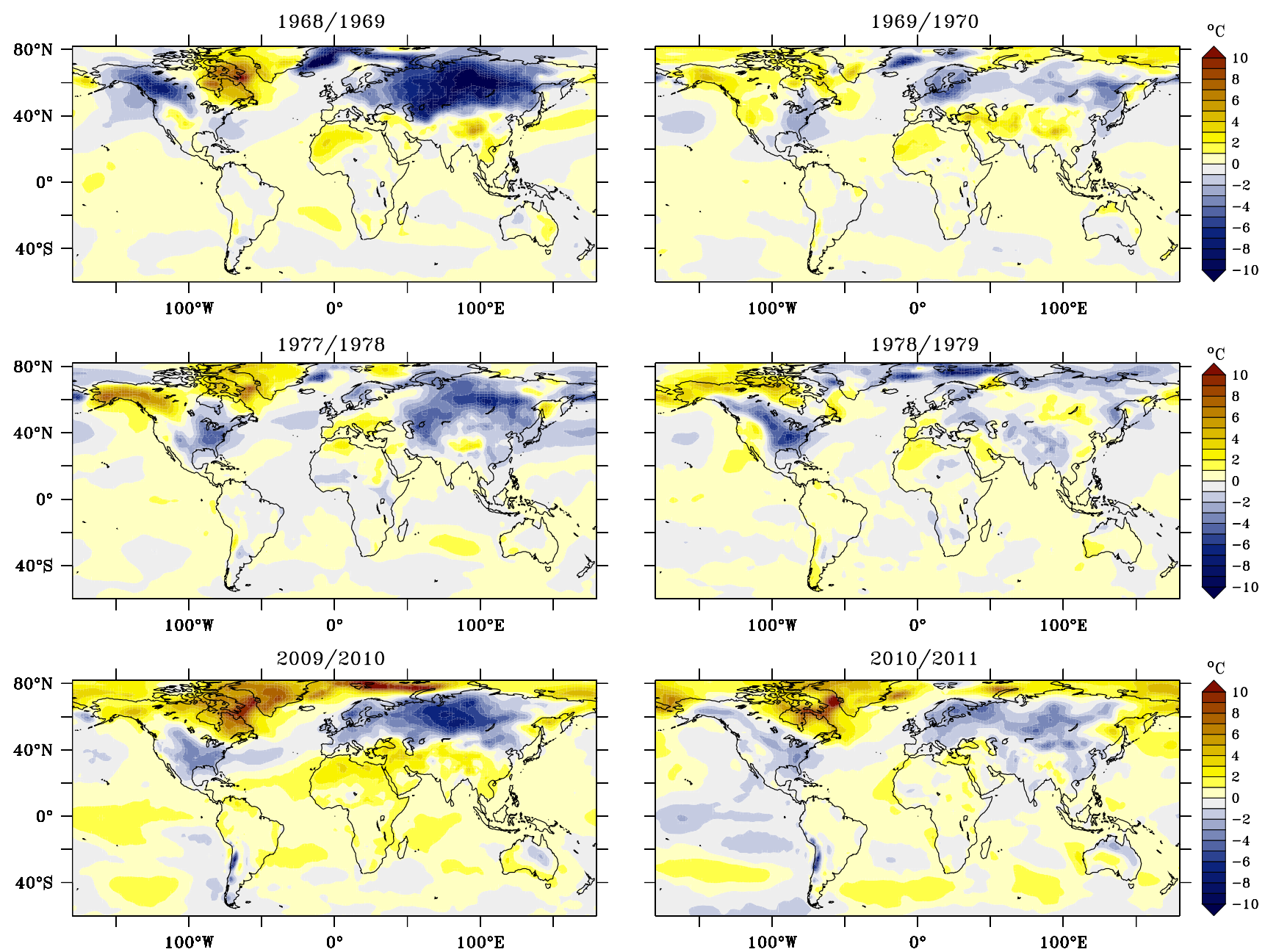

Fig. 9 Winter mean surface air temperature anomalies calculated from the NCEP/NCAR reanalysis dataset for years in which a pair of AMOC minima are seen in consecutive winters. Events shown are

ensemble also found no significant correlation between March 1978 and the following winter, indicating that this period did not experience a re-emergence event.

To further examine the strong indicators of reemergence for 1968/69 we plot surface and subsurface temperature anomalies for the region $5-65^{\circ} \mathrm{N}, 80-10^{\circ} \mathrm{W}$. An SST anomaly pattern similar in amplitude and distribution to the one presented in Fig. 11 is present in March 1969 (Fig. 13a). After persistent AO negative atmospheric conditions over the winter months this anomaly is coherent down to the base of the winter mixed layer (Fig. 13d). The pattern continues to persist into September at the winter mean mixed layer depth, below the shallow summer mixed layer (Fig. 13e), and through to January of 1970 (Fig. 13f), where the seasonal mixing returns the anomaly to the surface (Fig. 13c). The SST anomaly in September of 1969 (Fig. $13 \mathrm{~b}$ ) is uncorrelated with the SST anomaly present in March 1969 (see Fig. 12b).
1969/70 (top), 1978/79 (middle), and 2010/11 (bottom). The winter of the first year is shown on the left and for the following year on the right

The mechanism of re-emergence, whereby temperature anomalies formed in the deep winter mixed layer are trapped subsurface by the shallow summer mixed layer and then reentrained into the mixed layer during the onset of the following winter occurs annually. However, in order to provide a memory to the atmosphere a strong and coherent SST anomaly pattern must form during the first winter. A strong negative $\mathrm{AO}$ or NAO state which is persistent throughout the winter would facilitate this. There are a number of individual AMOC minima events which occur in the composite time series (Fig. 2), some of which are associated with negative NAO states, some of which are not. A possible explanation for why re-emergence events only occurred during strong negative AO states is that these events are consistently stable over the North Atlantic sector throughout winter (December to March). To examine this we construct a time series of the maximum monthly NAO index occurring during the winter months (DJFM). The mean and standard deviation of this 

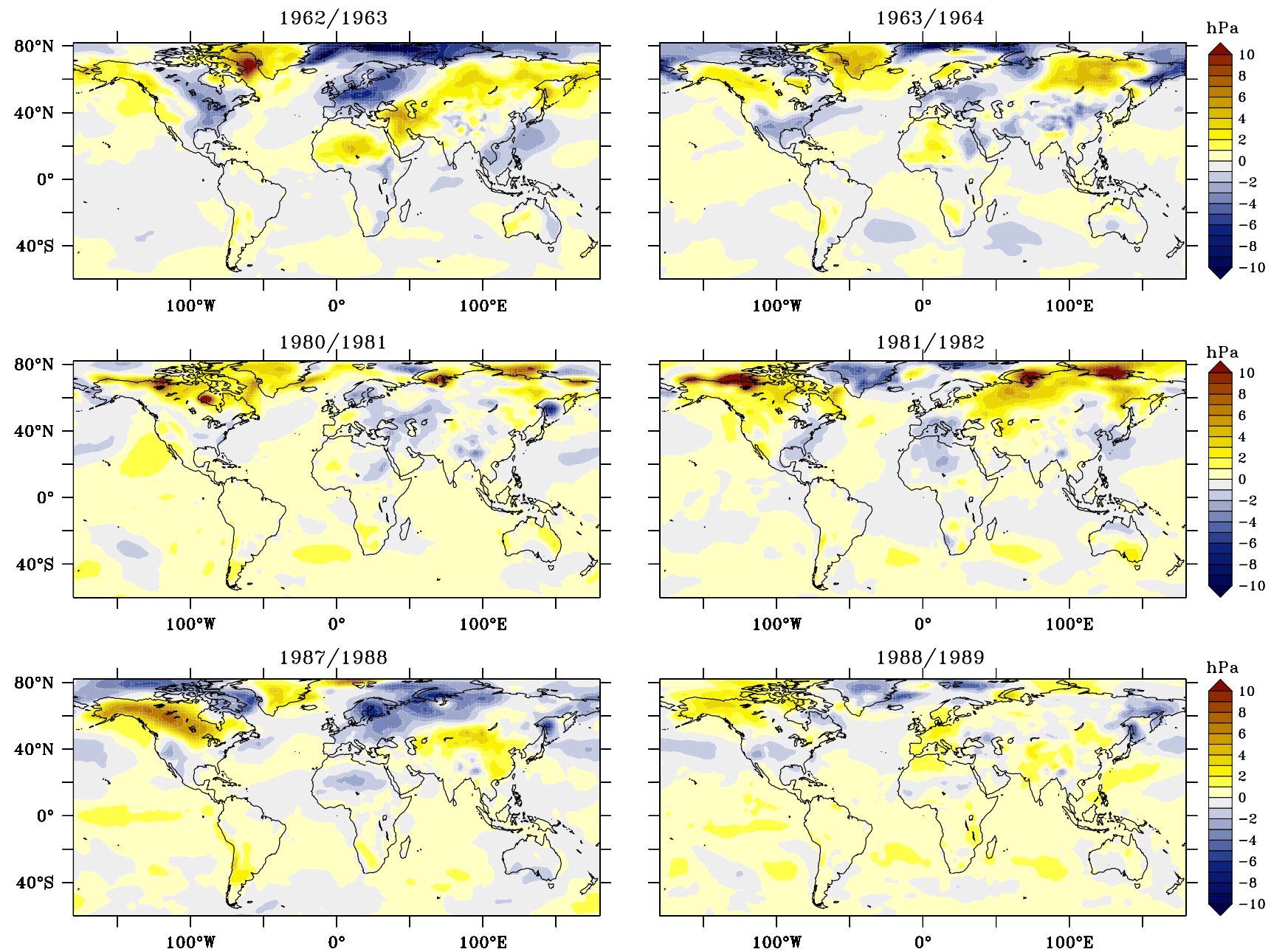

Fig. 10 Winter mean surface air temperature anomalies calculated from the NCEP/NCAR reanalysis dataset for years in which a single minima is seen. Events shown are the winters of 1962/63 (top),

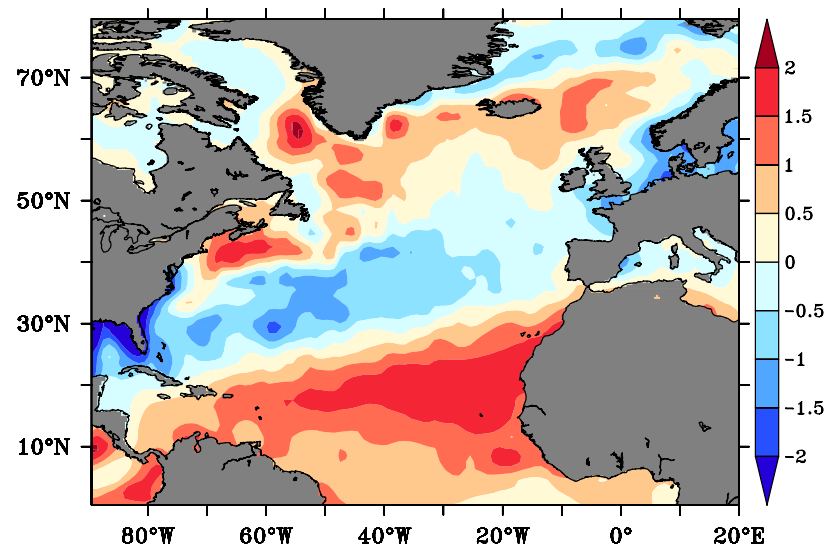

Fig. 11 March 2010 SST anomalies obtained from the NOAA OI dataset
1980/81 (middle), and 1986/87 (bottom). The winter of this year is shown on the left and for the following year when no AMOC minima is seen on the right

time series are 1.7 and 1.22 respectively. For the $1968 / 69$ and 2009/10 winters the maximum monthly mean NAO index reached during winter was -1.4 and -1.5 respectively, around 2.5 standard deviations lower than the mean winter maximum. The maximum NAO index during winter of 1977/78 was also anomalously low at $-0.5,1.75$ standard deviations below the mean. The winter maximum NAO index for the three individual events examined (1962/63, 1980/81 and 1987/88) were all within 0.5 standard deviations of the mean.

Interestingly the responses in the AMOC are stronger for $1978 / 79$ than for 1969/70, indicating that processes other than re-emergence might be important for providing memory to the atmosphere from one winter to the next, resulting in the wind stress anomalies which provide the Ekman anomaly in two consecutive winters. Of course it is also possible that two 


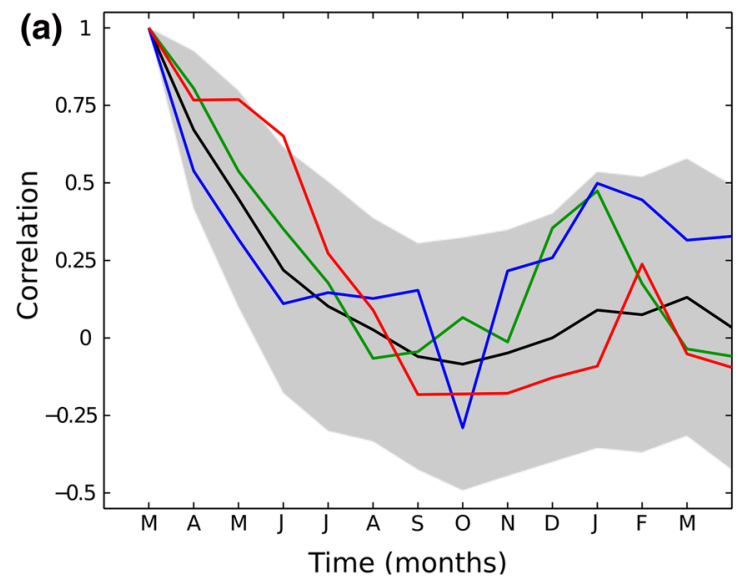

Fig. 12 One-year pattern correlation function for North Atlantic SSTAs $\left(5^{\circ} \mathrm{N}-65^{\circ} \mathrm{N}, 80-10^{\circ} \mathrm{W}\right)$. a Shows correlations from EN3 from March 2010-March 2011 (green), March 1969-March 1970 (blue), March 1978-March 1979 (red), and a 50-year (1960-2011) average (black). b Shows the equivalent from the five simulations which comprise the NEMO ORCA025 ensemble. March 1969-March 1970

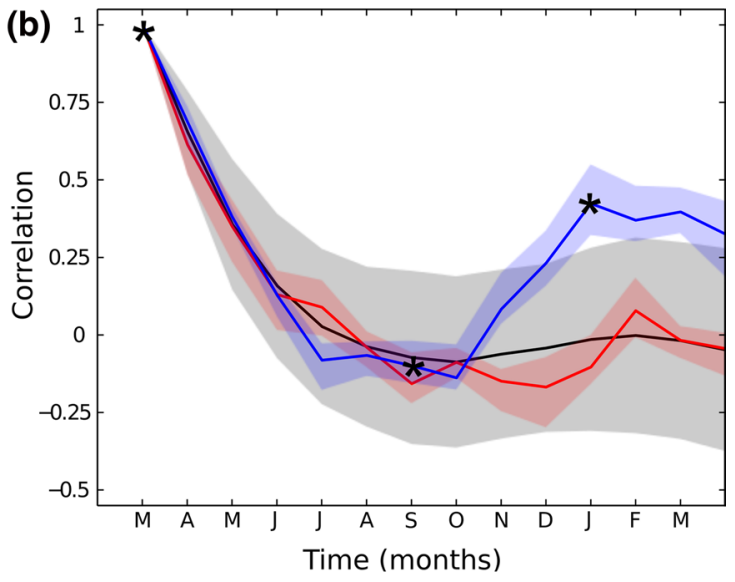

(blue) and March 1978-March 1979 (red) are shown. The lighter underlay for each line shows the range of the ensemble. The asterisks on the blue curve indicate the dates in 1969/70 which are presented in Fig. 13. For both panels the grey shading denotes the range (2 standard deviations) of correlation found in the a 1960-2011 and b 1958-2001 periods

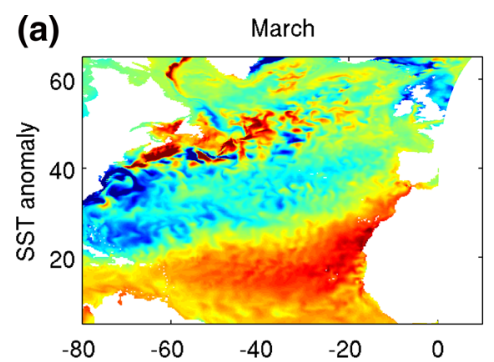

(d)

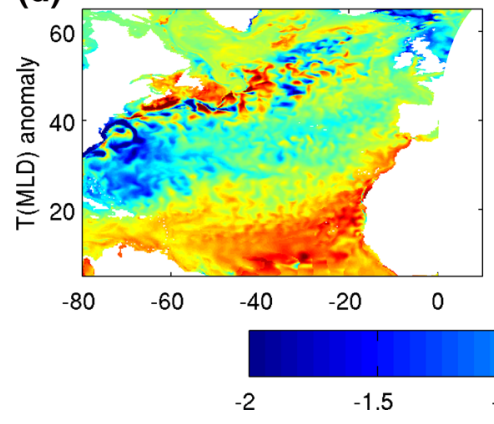

(b)

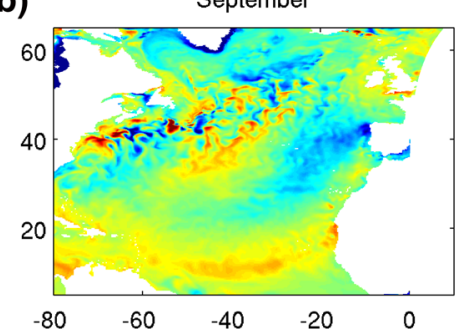

(e)

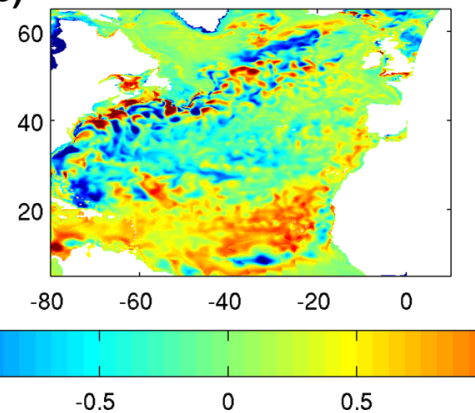

(c)

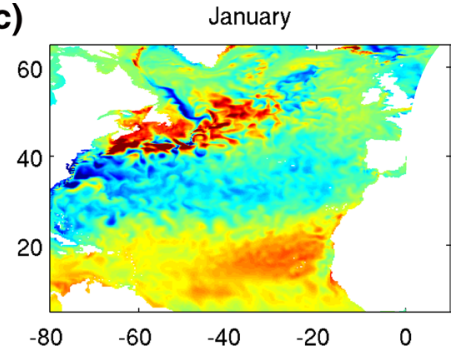

(f)

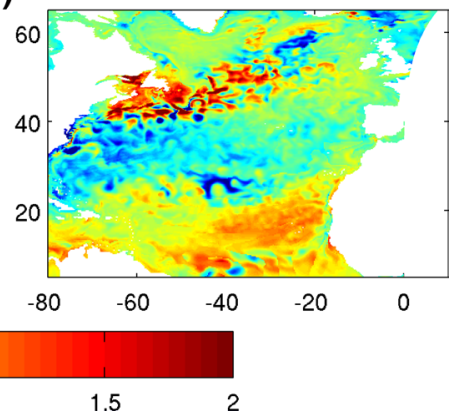

Fig. 13 Evolution of temperature anomalies from March 1969 to January 1970. SST anomalies (top row) and temperature anomalies at the base of the winter mixed layer (bottom row) from simulation

consecutive events occur by chance, and that no processes for providing memory from one winter to the next are involved.

\section{Summary and discussion}

In light of the anomalous minima events recorded in the AMOC for the winters of $2009 / 10$ and $2010 / 11$ by the $26^{\circ} \mathrm{N}$
N102 are shown for March 1969 (left column), September 1969 (middle column) and January 1970 (right column). Data are low pass filtered and then a mean seasonal cycle is removed

array (McCarthy et al. 2012) we employ an ensemble comprising five $1 / 4^{\circ}$ ocean model realisations to investigate how frequently these events have occurred in the past, and in particular whether there are mechanisms which might give rise to multiple events occurring in consecutive winters.

We first make comparisons between two model integrations (one $1 / 4^{\circ}$ and one $1 / 12^{\circ}$ ) which cover the period for which we have observations and determine that the NEMO 
ORCA ocean model is able to adequately reproduce the interannual variability of the AMOC captured by the mooring array, as well as the timing and amplitude of the anomalously strong minima which occur during the winters of 2009/10 and $2010 / 11$. The model is not able to capture all of the variability seen in the observations, and we do not expect it to given that around $30 \%$ of the variability is chaotic (Hirschi et al. 2013). The modelled amplitudes of the 2009/10 and 2010/11 events are slightly lower than observed, but so are both the mean and standard deviation of the AMOC represented in the model.

Examining the ensemble of NEMO runs which extend back to 1958 we have identified a number of events for which a strong reduction of the AMOC transport occurred. In some cases (e.g. 1962) these are individual events, but we also identify two pairs of events which occur in consecutive years during 1969/70 and 1978/79, which are historical analogues of the recently observed events. A possible third weaker analogue occurred in 1997/98.

We compare boreal winter atmospheric conditions for the years during which extreme negative anomalies in the AMOC were observed. The AMOC minimum event which occurred in the winter of 1962 coincides with an extended period of negative NAO, but no significant AO index. Other examples of individual events such as in 1981 and 1990 do not coincide with negative NAO states. In fact 1990 corresponds to one of the strongest positive AO and NAO indices for the period we examine. The pairs of events identified in 1969/70, 1978/79 and 2010/11 are all associated with strong negative AO indices, with particularly strong SLP patterns over the North Atlantic sector, and corresponding with strongly negative NAO indices. The event in the winter of 2009/10 coincides with one of the strongest negative values of the NAO index since records began in 1860, and there is evidence that the re-emergence mechanism contributed to persistence of the SST anomalies (Taws et al. 2011), and to the renewed development of negative NAO conditions (Buchan et al. 2014). We show here that the events of 1968/69 are also connected to an occurrence of reemergence, but the equally strong, if not stronger, AMOC minima seen in 1978/79 are not linked to a re-emergence of SST anomalies. SAT anomalies for all 3 events in 1969/70, 1978/79 and 2010/11 show a strong negative anomaly which covers much of Siberia, and other studies suggest that mechanisms related to sea ice cover over the Arctic and North Atlantic (e.g. Deser et al. (2007)) or to snow cover and thickness over Eurasia (Peings et al. 2012; Fletcher et al. 2009; Gong et al. 2004, 2003) may provide memory to the atmosphere which allows the negative NAO conditions over the North Atlantic sector to persist.

The minimum of the events frequently coincides with anomalously strong southward Ekman transport, which constitutes around half of the anomaly. We find that the simulations also capture a substantial amount of the low frequency variability of the UMO transport, indicating that this signal is also surface forced. It may be Sverdrup transport (Duchez et al. 2014b) or related to other mechanisms such as a lagged ocean response to the surface forcing such as the one described by Sinha et al. (2013), whereby changes in windstress influence ocean transport through adjustments of the vertical velocity and vortex stretching. Some of the model runs respond strongly for a given event whilst others show weaker responses, indicating that the events are not purely a response to the surface forcing but that there is some dependence on the ocean state or that ocean physics may affect the strength or timing of the nonEkman component of the anomalies. For example, a study which compared two of the simulations used here (N102 and N112) found that up to $30 \%$ of the total variability of the AMOC is attributable to chaotic processes such as mesoscale eddies and internal and planetary waves (Hirschi et al. 2013). Bryden et al. (2014) examine the 2009/10 event and conclude that some of the observed reduction is due to modes of ocean variability which are not associated with recent atmospheric forcing. Understanding these modes of variability could lead to improvements in the model representation of such events.

An interesting implication of the association of the extreme negative events with negative AO patterns and the re-emergence of SST anomalies is that it may be possible to predict the onset of negative NAO conditions and a second consecutive AMOC minimum (Maidens et al. 2013). There may also be scope for improved prediction of the AMOC for a third consecutive winter, since the anomaly composite reveals that there are no cases since 1958 where we find three or more consecutive extreme negative events.

Acknowledgments This work was supported by the NERC funded RAPID-WATCH project VALOR (NE/G007772/1) and was also part of the DRAKKAR project. Data from the RAPID-WATCH MOC monitoring project are funded by the Natural Environment Research Council and are freely available from www.noc.soton.ac. uk/rapidmoc. Sarah Taws was funded by a NERC Quota Studentship, with added support from the UK Met Office. NCEP Reanalysis Derived data were provided by the NOAA/OAR/ESRL PSD, Boulder, Colorado, USA, from their Web site at http://www.esrl.noaa.gov/psd/. NAO Index Data was provided by the Climate Analysis Section, NCAR, Boulder, USA. We thank two anonymous reviewers for their useful and constructive comments.

\section{Appendix: Decomposition of the AMOC}

Ocean models typically output the northward velocity for each grid box, which allows us to exactly compute the $\operatorname{AMOC}(\Psi)$ in the model, i.e.

$\Psi(y, z)=\int_{z}^{0} \int_{x_{w}}^{x_{e}} v\left(x, y, z^{\prime}\right) \quad d x d z^{\prime}$. 
In order to make comparisons with the observations taken at $26^{\circ} \mathrm{N}$ we may also compute components of the transport corresponding to those measured by the $26^{\circ} \mathrm{N}$ observing array, namely the Florida Straits transport, $\Psi_{F S T}$, the geostrophic (or thermal wind) transport, $\Psi_{g e o}$ and the Ekman transport, $\Psi_{\text {ekm }}$.

$\Psi_{F S T}$ is computed by integrating the meridional velocity, $v$, through the Florida Straits (between Florida, $x_{w}$, and the Bahamas, $x_{B h}$ ), and from the maximum depth of the Florida Straits $H_{F}$ to the surface,

$z^{\prime}$ is a dummy integration variable. $\Psi_{g e o}$, the baroclinic geo-

$\Psi_{F S T}=\int_{H_{F}}^{0} \int_{x_{w}}^{x_{B h}} v\left(x, z^{\prime}\right) \quad d x d z^{\prime}$.

strophic component arising from zonal density gradients across the Atlantic basin is

$\Psi_{\text {geo }}(z)=\int_{z}^{0} \int_{x_{B h}}^{x_{e}}\left(v_{\text {geo }}-\bar{v}_{\text {comp }}\right) \quad d x d z^{\prime}$,

where $v_{g e o}$ and $\bar{v}_{\text {comp }}$ are

$v_{g e o}(x, z)=-\frac{g}{\rho^{*} f} \int_{-H(x)}^{z} \frac{\partial \rho}{\partial x} d z^{\prime}$

and

$\bar{v}_{\text {comp }}(x, z)=\frac{1}{H(x)} \int_{-H(x)}^{0} v_{g e o}\left(x, z^{\prime}\right) \quad d z^{\prime}+\bar{v}_{F S T}$

respectively, $x_{e}$ is the easternmost extent of the Atlantic (i.e. Africa), $H(x)$ is the maximum depth of the basin as a function of longitude, $g$ being the Earth's gravitational acceleration, $\rho$ the in-situ density, $f$ the Coriolis parameter, and $\rho^{*}$ a reference density. $\bar{v}_{F S T}$ is

$\bar{v}_{F S T}=\frac{\Psi_{F S T}}{A}$

with $A$ being the cross-sectional area of the Atlantic basin east of the Bahamas.

We define $\Psi_{\text {ekm }}$, the Ekman (wind driven) component, here as a function of latitude and depth compensated by a section mean return flow to ensure no net transport,

$\Psi_{e k m}(y, z)=\int_{-H_{\max }(y)}^{z} \int_{x_{w}}^{x_{e}}\left(v_{e k m}-\bar{v}_{e k m}\right) \quad d x d z^{\prime}$,

where $v_{e k m}$ and $\bar{v}_{e k m}$ are

$v_{e k m}=-\frac{1}{\left(\rho^{*} f L \Delta_{z}\right)} \int_{x_{w}}^{x_{e}} \tau_{x} d x$

and

$\bar{v}_{e k m}=-\frac{1}{\left(\rho^{*} f A\right)} \int_{x_{w}}^{x_{e}} \tau_{x} d x$ respectively, $L$ being the basin width, $\Delta_{z}$ the Ekman depth, and $H_{\max }(y)$ the latitudinally dependent maximum depth of the basin. The Ekman depth, $\Delta_{z}$, which defines the base of the Ekman layer in which the wind driven transport occurs we chose to be $100 \mathrm{~m}$. The choice of $\Delta_{z}$ does not strongly affect the resulting overturning profile. Note that the compensation term associated with the Ekman transport could equally be added to $\bar{v}_{\text {comp }}$, but that it will be small compared with the other terms.

Therefore at $26.5^{\circ} \mathrm{N}$ the AMOC transport can be considered as the sum of these components plus a residual term, $\Psi_{\text {res }}$,

$\Psi=\Psi_{F S T}+\Psi_{g e o}+\Psi_{e k m}+\Psi_{\text {res }}$.

where $\Psi_{\text {res }}$ can be obtained by rearranging Eq. (10). If averaged over a time longer than a few cycles of the local inertial period the residual term is small (order $1 \mathrm{~Sv}$ ), and can be ignored. It should be noted, however, that this term can dominate the AMOC variability at near-inertial time scales (Blaker et al. 2012; Sevellec et al. 2013).

\section{References}

Alexander MA, Deser C (1995) A mechanism for the recurrence of wintertime mid-latitude SST anomalies. J Phys Oceanogr 25:122-137

Baehr J, Haak H, Alderson S, Cunningham SA, Jungclaus JH, Marotzke J (2007) Timely detection of changes in the meridional overturning circulation at $26 \mathrm{~N}$ in the Atlantic. J Clim 20(23):5827-5841

Baehr J, Cunningham SA, Haak H, Heimbach P, Kanzow T, Marotzke J (2009) Observed and simulated daily variability of the meridional overturning circulation at $26.5^{\circ} \mathrm{N}$ in the Atlantic. Ocean Sci Discuss 5:575-589

Balan Sarojini B, Gregory J, Tailleux R, Bigg GR, Blaker AT, Cameron DR, Edwards NR, Megann AP, Shaffrey L, Sinha B (2011) High frequency variability of the Atlantic meridional overturning circulation. Ocean Sci 7(4):471-486. doi:10.5194/ os-7-471-2011

Barnier B, Madec G, Penduff T, Molines JM, Treguier AM, Sommer JL, Beckmann A, Biastoch A, Bning C, Dengg J, Derval C, Durand E, Gulev S, Remy E, Talandier C, Theetten S, Maltrud M, McClean J, de Cuevas B (2006) Impact of partial steps and momentum advection schemes in a global ocean circulation model at eddy-permitting resolution. Ocean Dyn 56:543-567

Bellucci A, Gualdi S, Scoccimarro E, Navarra A (2008) NAO-ocean circulation interactions in a coupled general circulation model. Clim Dyn 31(7-8):759-777

Blaker AT, Hirschi JJM, Sinha B, de Cuevas BA, Alderson SG, Coward AC, Madec G (2012) Large near-inertial oscillations of the Atlantic meridional overturning circulation. Ocean Model 42:5056. doi:10.1016/j.ocemod.2011.11.008

Brodeau L, Barnier B, Penduff T, Treguier AM, Gulev S (2010) An ERA 40 based atmospheric forcing for global ocean circulation models. Ocean Model 31(3-4):88-104

Broeker WS (1987) The biggest chill. Nat Hist Mag 97:74-82

Bryden H, King BA, McCarthy GD, McDonagh EL (2014) Impact of a $30 \%$ reduction in Atlantic meridional overturning during 20092010. Ocean Sci Discuss 11:789-810 
Buchan J, Hirschi JJM, Blaker AT, Sinha B (2014) Influence of North Atlantic sea surface temperature anomalies on the NAO in December 2010. Mon Weather Rev 142:922-932

Cassou C, Deser C, Alexander MA (2007) Investigating the impact of reemerging sea surface temperature anomalies on the winter atmospheric circulation over the North Atlantic. J Clim 20:35103526. doi:10.1175/JCLI4202.1

Chidichimo MP, Kanzow T, Cunningham SA, Johns WE, Marotzke J (2010) The contribution of eastern-boundary density variations to the Atlantic meridional overturning circulation at $26.5 \mathrm{~N}$. Ocean Sci 6:475-490

Ciasto LM, Alexander MA, Deser C, England MH (2011) On the persistence of cold-season SST anomalies associated with the annular modes. J Clim 24(10):2500-2515

Cunningham SA, Kanzow T, Rayner D, Baringer MO, Johns WE, Marotzke J, Longworth HR, Grant EM, Hirschi JJM, Beal LM, Meinen CS, Bryden HL (2007) Temporal variability of the Atlantic meridional overturning circulation at $26.5^{\circ} \mathrm{N}$. Science 317:935-938. doi:10.1126/science.1141304

D'Andrea F, Czaja A, Marshall J (2005) Impact of anomalous ocean heat transport on the North Atlantic oscillation. J Clim 18(23):4955-4969

Dee DP, Uppala SM, Simmons AJ, Berrisford P, Poli P, Kobayashi S, Andrae U, Balmaseda MA, Balsamo G, Bauer P, Bechtold P, Beljaars ACM, van de Berg L, Bidlot J, Bormann N, Delsol C, Dragani R, Fuentes M, Geer AJ, Haimberger L, Healy SB, Hersbach H, Hlm EV, Isaksen L, Kllberg P, Khler M, Matricardi M, McNally AP, Monge-Sanz BM, Morcrette JJ, Park BK, Peubey C, de Rosnay P, Tavolato C, Thpaut JN, Vitart F (2011) The ERAInterim reanalysis: configuration and performance of the data assimilation system. Q J R Meteorol Soc 137(656):553-597. doi: $10.1002 /$ qj. 828

Deser C, Tomas RA, Peng S (2007) The transient atmospheric circulation response to North Atlantic SST and sea ice anomalies. J Clim 20(18):4751-4767

Deshayes J, Treguier AM, Barnier B, Lecointre A, Sommer JL, Molines JM, Penduff T, Bourdalle-Badie R, Drillet Y, Garric G, Benshilla R, Madec G, Biastoch A, Boning CW, Scheinert M, Coward AC, Hirschi JJM (2013) Oceanic hindcast simulations at high resolution suggest that the Atlantic MOC is bistable. Geophys Res Lett 40(12):3069-3073. doi:10.1002/grl.50534

Dickson RR, Brown J (1994) The production of North Atlantic deep water: sources, rates, and pathways. J Geophys Res Oceans 99(C6):12,319-12,341. doi:10.1029/94JC00530

DRAKKAR Group (2007) Eddy-permitting ocean circulation hindcasts of past decades. Clivar Exch 12(3):8-10

Duchez A, Frajka-Williams E, Castro N, Hirschi JJM, Coward A (2014a) Seasonal to interannual variability in density around the Canary Islands and their influence on the Atlantic meridional overturning circulation at 26N. J Gephys Res Oceans 119. doi:10.1002/2013JC009416

Duchez A, Hirschi JJM, Cunningham SA, Blaker AT, Bryden HL, de Cuevas BA, Atkinson CP, McCarthy GD, Frajka-Williams E, Rayner D, Smeed D, Mizielinski MS (2014b) A new index for the Atlantic Meridional overturning circulation at $26 \mathrm{~N}$. J Clim. doi:10.1175/JCLI-D-13-00052.1

Fletcher CG, Hardiman SC, Kushnir PJ (2009) The dynamical response to snow cover perturbations in a large ensemble of atmospheric GCM integrations. J Clim 22:1208-1222

Ganachaud A, Wunsch C (2000) Improved estimates of global ocean circulation, heat transport and mixing from hydrographic data. Nature 408:453-457. doi:10.1038/35044048

Gastineau G, D'Andrea F, Frankignoul C (2013) Atmospheric response to the North Atlantic Ocean variability on seasonal to decadal time scales. Clim Dyn 40(9-10):2311-2330. doi:10.1007/s00382-012-1333-0
Gong G, Entekhabi D, Cohen J (2003) Modeled Northern Hemisphere Winter Climate Response to Realistic Siberian Snow Anomalies. Journal of Climate 16:3917-3931. doi:10.1175/1520-0442(2003)016<3917:MNHWCR>2.0.CO;2

Gong G, Entekhabi D, Cohen J, Robinson D (2004) Sensitivity of atmospheric response to modeled snow anomaly characteristics. J Geophys Res 109(D06107). doi:10.1029/2003JD004160

Grist JP, Josey SA, Marsh R, Good SA, Coward AC, de Cuevas BA, Alderson SG, New AL, Madec G (2010) The roles of surface heat flux and ocean heat transport convergence in determining Atlantic Ocean temperature variability. Ocean Dyn 60(4):771-790. doi:10.1007/s10236-010-0292-4

Grist JP, Josey SA, Marsh R (2012) Surface estimates of the Atlantic overturning in density space in an eddy-permitting ocean model. J Geophys Res 117(C06012). doi:10.1029/2011JC007752

Heape R, Hirschi JJM, Sinha B (2013) Asymmetric response of European pressure and temperature anomalies to NAO positive and NAO negative winters. Weather 68(3):73-80. doi:10.1002/wea.2068

Hermanson L, Eade R, Robinson NH, Dunstone NJ, Andrews MB, Knight JR, Scaife AA, Smith DM (2014) Forecast cooling of the Atlantic subpolar gyre and associated impacts. Geophys Res Lett. doi:10.1002/2014GL060420

Hirschi J, Marotzke J (2007) Reconstructing the meridional overturning circulation from boundary densities and the zonal wind stress. J Phys Oceanogr 37:743-763

Hirschi J, Baehr J, Marotzke J, Stark J, Cunningham S, Beismann JO (2003) A monitoring design for the Atlantic meridional overturning circulation. Geophys Res Lett 30(7):1413. doi:10.1029/200 2GL016776

Hirschi J, Blaker AT, Sinha B, de Cuevas B, Alderson SG, Coward AC, Madec G (2013) Chaotic variability of the meridional overturning circulation on subannual to interannual timescales. Ocean Sci 9:3191-3238. doi:10.5194/osd-9-3191-2012

Hirschi JJM, Sinha B (2007) Negative NAO and cold Eurasian winters: how exceptional was the winter of $1962 / 1963$ ? Weather 62(2):43-48. doi:10.1002/wea.34

Hurrell JW (1995) Decadal trends in the North Atlantic Oscillation regional temperatures and precipitation. Science 269:676-679

Ingleby B, Huddleston M (2007) Quality control of ocean temperature and salinity profiles: historical and real-time data. J Mar Syst 65:158-175. doi:10.1016/j.jmarsys.2005.11.019

Johns WE, Baringer MO, Beal LM, Cunningham SA, Kanzow T, Bryden HL, Hirschi JJM, Marotzke J, Meinen C, Shaw B, Curry R (2011) Continuous, array-based estimates of Atlantic Ocean heat transport at $26.5^{\circ} \mathrm{N}$. J Clim 24(10):2429-2449. doi:10.1175/ 2010JCLI3997.1

Jourdan D, Balopoulos E, Garcia-Fernandez M, Maillard C (1998) Objective analysis of temperature and salinity historical data set over the mediterranean basin. Technical report IEEE

Kalnay E, Kanamitsu M, Kistler R, Collins W, Deaven D, Gandin L, Iredell M, Saha S, White G, Woollen J, Zhu Y, Chelliah M, Ebisuzaki W, Higgins W, Janowiak J, Mo KC, Ropelewski C, Wang J, Leetmaa A, Reynolds R, Jenne R, Joseph D (1996) The NCEP/NCAR 40-year reanalysis project. Bull Am Meteorol Soc 77:437-471

Kanzow T, Johnson HL, Marshall DP, Cunningham SA, Hirschi JJM, Mujahid A, Bryden HL, Johns WE (2009) Basinwide integrated volume transports in an eddy-filled ocean. J Phys Oceanogr 39:3091-3110. doi:10.1175/2009JPO4185.1

Kanzow T, Cunningham SA, Johns WE, Hirschi JJM, Barringer MO, Meinen CS, Chidichimo MP, Atkinson CP, Beal LM, Bryden HL, Collins J (2010) Seasonal variability of the Atlantic meridional overturning circulation at 26.5N. J Clim 23:5678-5698

Kuhlbrodt T, Griesel A, Montoya M, Levermann A, Hofmann M, Rahmstorf S (2007) On the driving processes of the Atlantic 
meridional overturning circulation. Rev Geophys 45(RG2001). doi:10.1029/2004RG000166

Large WG, Yeager SG (2004) Diurnal to decadal global forcing for ocean and sea-ice models: the data sets and flux climatologies. Technical Report TN-460+STR(NCAR)

Large WG, Yeager SG (2008) The global climatology of an interannually varying air-sea flux data set. Clim Dyn. doi:10.1007/ s00382-008-0441-3

Levitus S, Conkright M, Boyer TP, O’Brian T, Antonov J, Stephens C, Johnson LSD, Gelfeld R (1998) World ocean database 1998. Technical report NESDIS 18, NOAA Atlas

L'Heureux M, Butler A, Jha B, Kumar A, Wang W (2010) Unusual extremes in the negative phase of the Arctic Oscillation during 2009. Geophys Res Lett 37(L10704). doi:10.1029/201 0GL043338

Lumpkin R, Speer K (2007) Global ocean meridional overturning. J Phys Oceanogr 37:2550-2562

Luo D, Zhu Z, Ren R, Zhong L, Wang C (2010) Spatial pattern and zonal shift of the North Atlantic oscillation. Part I: a dynamical interpretation. J Atmos Sci 67:2805-2826. doi:10.1175/2010 JAS3345.1

Madec G (2008) NEMO ocean engine. Note du Pole de modélisation. Institut Pierre-Simon Laplace (IPSL), France 27:1288-1619

Maidens A, Arribas A, Scaife AA, Maclachlan C, Peterson D, Knight J (2013) The influence of surface forcings on prediction of the North Atlantic oscillation regime of Winter 2010-2011. Mon Weather Rev 141(11):3801-3813. doi:10.1175/MWR-D-13-00033.1

Marshall J, Johnson H, Goodman J (2000) A study of the interaction of the North Atlantic oscillation with ocean circulation. J Clim 14:1399-1421. doi:10.1175/1520-0442(2001)014<1399:ASOTI $\mathrm{O}>2.0 . \mathrm{CO} ; 2$

McCarthy G, Frajka-Williams E, Johns WE, Baringer MO, Meinen CS, Bryden HL, Rayner D, Duchez A, Cunningham SA (2012) Observed interannual variability of the Atlantic meridional overturning circulation at 26.5N. Geophys Res Lett 39(L19609). doi: $10.1029 / 2012$ GL052933

NCAR (2012a) The climate data guide: Hurrell North Atlantic Oscillation (NAO) Index (station-based). http://climatedataguide.ucar. edu/guidance/hurrell-north-atlantic-oscillation-nao-index-stationbased

NCAR (2012b) The climate data guide: Hurrell wintertime SLPbased Northern Annular Mode (NAM) Index. http://climatedata guide.ucar.edu/guidance/hurrell-wintertime-slp-based-northernannular-mode-nam-index

NOAA (2013) 2009/2010 Cold season. http://www.ncdc.noaa.gov/ special-reports/2009-2010-cold-season.html

Osborn TJ (2011) Winter 2009/2010 temperatures and a record breaking North Atlantic Oscillation index. Weather 66:19-21

Peings Y, Saint-Martin D, Douville H (2012) A numerical sensitivity study of the influence of siberian snow on the northern annular mode. J Clim 25:592-607. doi:10.1175/JCLI-D-11-00038.1

Quartly GD, de Cuevas BA, Coward AC (2013) Mozambique channel eddies in GCMs: a question of resolution and slippage. Ocean Model 63:56-67
Rayner D, Hirschi JJM, Kanzow T, Johns WE, Wright PG, FrajkaWilliams E, Bryden HL, Meinen CS, Barringer MO, Marotzke J, Beal LM, Cunningham SA (2011) Monitoring the Atlantic meridional overturning circulation. Deep Sea Res Part II Top Stud Oceanogr 58(17-18):1744-1753

Reynolds RW, Rayner NA, Smith TM, Stokes DC, Wang W (2002) An improved in situ and satellite sst analysis for climate. J Clim 15:1609-1625

Rhines PB, Häkkinen S (2003) Is the oceanic heat transport in the North Atlantic irrelevant to the climate in Europe? ASOF Newsl 1:13-17

Sevellec F, Fedorov AV (2013) The leading, interdecadal eigenmode of the Atlantic meridional overturning circulation in a realistic ocean model. J Clim 26:2160-2183. doi:10.1175/JCLI-D-11-00023.1

Sevellec F, Hirschi JJM, Blaker AT (2013) On the super-inertial resonance of the Atlantic meridional overturning circulation. J Phys Oceanogr 43:2661-2672. doi:10.1175/JPO-D-13-092.1

Sinha B, Blaker AT, Hirschi JJM, Bonham S, Brand M, Josey S, Smith R, Marotzke J (2012) Mountain ranges favour vigorous Atlantic meridional overturning. Geophys Res Lett 39(L02705):7. doi:10 .1029/2011GL05048

Sinha B, Topliss B, Blaker AT, Hirschi JJM (2013) A numerical model study of the effects of interannual timescale wave propagation on the predictability of the Atlantic meridional overturning circulation. J Geophys Res. doi:10.1029/2012JC008334

Sonnewald M, Hirschi JJM, Marsh R (2013) Oceanic dominance of interannual subtropical North Atlantic heat content variability. Ocean Sci Discuss 10:27-53. doi:10.5194/osd-10-27-2013

Steele M, Morley R, Ermold W (2001) PHC: a global ocean hydrography with a high quality Arctic Ocean. J Clim 14:2079-2087

Taws SL (2013) Seasonal re-emergence of sea surface temperature anomalies in the North Atlantic: an observational and ocean model study. PhD Thesis, University of Southampton

Taws SL, Marsh R, Wells NC, Hirschi JJM (2011) Re-emerging ocean temperature anomalies in late-2010 associated with a repeat negative NAO. Geophys Res Lett 38(L20601). doi:10.1029/201 $1 \mathrm{GL} 048978$

Thompson DWJ, Wallace JM (2000) Annular modes in the extratropical circulation. Part I: month-to-month variability. J Clim 13:1000-1016

Timmerman A, Goosse H, Madec G, Fichefet T, Ethe C, Dulire V (2005) On the representation of high latitude processes in the ORCA-LIM global coupled sea-ice ocean model. Ocean Model $8: 175-201$

U.S. Department of Commerce (2006) U.S. Department of Commerce, National Oceanic and Atmospheric Administration, National Geophysical Data Center: 2-minute Gridded Global Relief Data (ETOPO2v2). http://www.ngdc.noaa.gov/mgg/global/etopo2.html

Wallace JM (2000) North Atlantic Oscillation/annular mode: two paradigms-one phenomenon. Q J R Meterol Soc 126(564):791-805. doi:10.1002/qj.49712656402

Zhao J, Johns W (2014) Wind-forced interannual variability of the Atlantic meridional overturning circulation at $26.5 \mathrm{~N}$. J Geophys Res Oceans 119:2403-2419. doi:10.1002/2013JC009407 